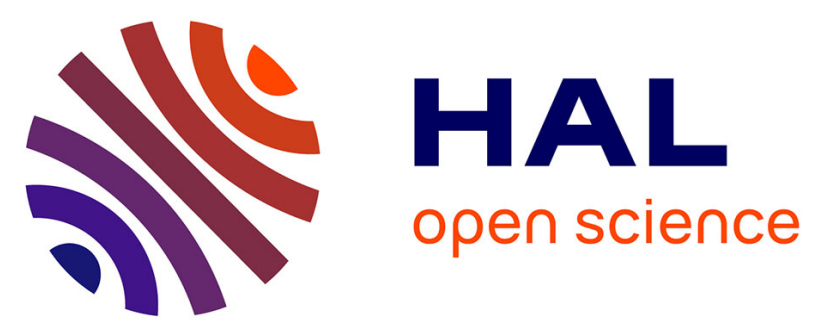

\title{
Organic chemistry in Titan s upper atmosphere and its astrobiological consequences: I. Views towards Cassini plasma spectrometer (CAPS) and ion neutral mass spectrometer (INMS) experiments in space
}

\author{
A. Ali, E. C. Sittler Jr., D. Chornay, B. R. Rowe, C Puzzarini
}

\section{To cite this version:}

A. Ali, E. C. Sittler Jr., D. Chornay, B. R. Rowe, C Puzzarini. Organic chemistry in Titan s upper atmosphere and its astrobiological consequences: I. Views towards Cassini plasma spectrometer (CAPS) and ion neutral mass spectrometer (INMS) experiments in space. Planetary and Space Science, 2015, 109-110, pp.46-63. 10.1016/j.pss.2015.01.015 . hal-01225626

HAL Id: hal-01225626

https://hal-univ-rennes1.archives-ouvertes.fr/hal-01225626

Submitted on 19 Nov 2015

HAL is a multi-disciplinary open access archive for the deposit and dissemination of scientific research documents, whether they are published or not. The documents may come from teaching and research institutions in France or abroad, or from public or private research centers.
L'archive ouverte pluridisciplinaire HAL, est destinée au dépôt et à la diffusion de documents scientifiques de niveau recherche, publiés ou non, émanant des établissements d'enseignement et de recherche français ou étrangers, des laboratoires publics ou privés. 


\title{
Organic Chemistry in Titan's Upper Atmosphere and its Astrobiological Consequences: I. Views towards Cassini Plasma Spectrometer (CAPS) and Ion Neutral Mass Spectrometer (INMS) Experiments in Space
}

\author{
A. Ali ${ }^{a, b *}$, E. C. Sittler Jr ${ }^{a}$, D. Chornay ${ }^{a, b}$, B. R. Rowe ${ }^{c}$, C. Puzzarini ${ }^{d} *$ \\ ${ }^{a}$ NASA Goddard Space Flight Center, Greenbelt, MD 20771, USA \\ ${ }^{\mathrm{b}}$ Department of Astronomy, University of Maryland, College Park, MD 20742, USA \\ ${ }^{\mathrm{C}}$ Institut de Physique de Rennes, Equipe: Astrochimie Experimentale, CNRS. \\ Universite de Rennes 1, Campus de Beaulieu, 35042 Rennes Cedex, France \\ d Dipartimento di Chimica "Giacomo Ciamician" Universita di Bologna, via Selmi 2. \\ I- 40126 Bologna, Italy \\ *Corresponding author: ashraf.ali@nasa.gov; cristina.puzzarini@unibo.it
}

\begin{abstract}
The discovery of carbocations and carbanions by lon Neutral Mass Spectrometer (INMS) and the Cassini Plasma Spectrometer (CAPS) instruments onboard the Cassini spacecraft in Titan's upper atmosphere is truly amazing for astrochemists and astrobiologists. In this paper we identify the reaction mechanisms for the growth of the complex macromolecules observed by the CAPS Ion Beam Spectrometer (IBS) and Electron Spectrometer (ELS). This identification is based on a recently published paper (Ali et al., Planet. Space Sci. 87, 96, 2013) which emphasizes the role of Olah's nonclassical carbonium ion chemistry in the synthesis of the organic molecules observed in Titan's thermosphere and ionosphere by INMS. The main conclusion of that work was the demonstration of the presence of the cyclopropenyl cation -the simplest Huckel's aromatic molecule- and its cyclic methyl derivatives in Titan's atmosphere at high altitudes. In this study, we present the transition from simple aromatic molecules to the complex ortho-bridged bi- and tri-cyclic hydrocarbons, e.g., $\mathrm{CH}_{2}{ }^{+}$mono- substituted naphthalene and phenanthrene, as well as the ortho- and peri-bridged tri-cyclic aromatic ring, e.g., perinaphthenyl cation. These rings could further grow into tetra-cyclic and the higher order ring polymers in Titan's upper atmosphere. Contrary to the pre-Cassini observations, the nitrogen chemistry of Titan's upper atmosphere is found to be extremely rich. A variety of $\mathrm{N}$-containing hydrocarbons including the $\mathrm{N}$-heterocycles where a $\mathrm{CH}$ group in the polycyclic rings mentioned above is replaced by an $\mathrm{N}$ atom, e.g., $\mathrm{CH}_{2}{ }^{+}$substituted derivative of quinoline (benzopyridine), are found to be dominant in Titan's upper atmosphere. The mechanisms for the formation of complex molecular anions are discussed as well. It is proposed that many closed-shell complex carbocations after their formation first, in Titan's upper atmosphere, undergo the kinetics of electron recombination to form openshell neutral radicals. These radical species subsequently might form carbanions via radiative electron attachment at low temperatures with thermal electrons. The classic example is the perinaphthenyl anion in Titan's upper atmosphere. Therefore, future astronomical observations of selected carbocations and corresponding carbanions are required to settle the key issue of molecular anion chemistry on Titan. Other than earth, Titan is the only
\end{abstract}


planetary body in our solar system that is known to have reservoirs of permanent liquids on its surface. The synthesis of complex biomolecules either by organic catalysis of precipitated solutes "on hydrocarbon solvent" on Titan or through the solvation process indeed started in its upper atmosphere. The most notable examples in Titan's prebiotic atmospheric chemistry are conjugated and aromatic polycyclic molecules, N-heterocycles including the presence of imino $>\mathrm{C}=\mathrm{N}-\mathrm{H}$ functional group in the carbonium chemistry. Our major conclusion in this paper is that the synthesis of organic compounds in Titan's upper atmosphere is a direct consequence of the chemistry of carbocations involving the ion-molecule reactions. The observations of complexity in the organic chemistry on Titan from the Cassini-Huygens mission clearly indicate that Titan is so far the only planetary object in our solar system that will most likely provide an answer to the question of the synthesis of complex biomolecules on the primitive earth and the origin of life.

Keywords: Titan; Upper atmosphere; Carbonium ions; Carbanions; Prebiotic chemistry; Astronomical observations. 


\section{Introduction}

Where does organic chemistry occur in the molecular universe (Gerin, 2013)? Prior to the CassiniHuygens arrival in the Saturn system, it was generally believed that only living organisms or once-living organisms on Earth, and interstellar space are the two places where organic molecules are/were synthesized extensively. However, the experimental measurements by the instruments onboard the Cassini orbiter spacecraft (Waite et al., 2004; Young et al., 2004) and the Huygens probe lander (Niemann et al., 2005) have changed this view. These measurements have significant implications on the textbook fundamentals of the chemistry of carbocations (Olah 1972, 1995) and carbanions (Cram 1965), and in the second place they suggest to give a new look at the abiotic synthetic organic chemistry. No other planets or their satellites in our solar system have been found to bear the level of chemical complexity that we can observe on Titan by means of the Cassini-Huygens Mission. The question is whether there is a link between the organic synthetic chemistry in Titan's atmosphere, the chemistry in space amongst stars, and the terrestrial prebiotic chemistry which influences the origin of building blocks of biomolecules (e.g. nucleotide bases). The topics of (1) the exogenous interstellar organics and transported by comets and meteorites to the early earth, and (2) the endogenous prebiotic chemistry in the atmosphere of primitive earth are of considerable interest, and are related to the question of the origin of life on earth. We therefore need to focus on understanding how simple organic molecules ultimately evolve into complex biopolymers thorough chemical processes. To which extent did the organic chemistry in space influence the origin of life on earth? Such a question could be answered through astrophysical observations of organic molecules in the atmosphere of extrasolar planets reminiscent of young earth, and by studying their similarities and differences in composition, structure and reactivity. In this perspective, the study of the molecular ions (carbocations and carbanions) and of the corresponding neutrals recently detected in Titan's upper atmosphere provides a unique opportunity (Waite et al. 2005, 2007, 2008, 2009; Coates et al. 2007; Vuitton et al. 2009a, 2009b).

The observation by Voyager encounters revealed that Titan's atmosphere primarily consists of molecular nitrogen $(>90 \%)$ with methane as the second most abundant molecule. Prior to the measurements by the Cassini spacecraft, a number of photochemical models (Yung et al., 1984; Wilson and Atreya, 2004) pointed out that the dissociation of nitrogen and methane, the two major neutral species in the upper atmosphere of Titan, by means of electron impact and solar ultraviolet photons initiates the chemistry of hydrocarbons and nitriles such as $\mathrm{HCN}, \mathrm{C}_{2} \mathrm{H}_{2}$ and $\mathrm{C}_{2} \mathrm{H}_{4}$. Most of these models involved neutral chemistry to explain the low-altitude (approximately $200 \mathrm{~km}$ to $400 \mathrm{~km}$ from the surface) haze formation. This view is drastically changed as a consequence of the recent measurements by the Cassini Ion Neutral Mass Spectrometer (INMS; Waite et al. 2004), the two Cassini Plasma Spectrometer (CAPS) sensors (Young et al. 2004), the lon Beam Spectrometer (CAPS-IBS) and the Electron Spectrometer (CAPS-ELS). These measurements have in fact revealed the presence of numerous carbocations in Titan's thermosphere and ionosphere (Waite et al. 2007, 2009; Vuitton et al., 2009a), detected by INMS (that cover the mass spectral range up to $100 \mathrm{amu}$ ) as well as by CAPS-IBS that extended the mass ranges with $\mathrm{m} / \mathrm{q}$ values up to 350 (Crary et al. 2009; Waite et al. 2008, 2009). Furthermore, CAPS-ELS provided evidence (Coates et al. 2007, 2009, 2010; Wellbrock et al. 2013; Waite et al. 2007, 2009; Vuitton et al. 2009b; Sittler et al. 2009) for the detection of massive negative ions (up 
to $13,800 \mathrm{amu}$ ), and in particular of very large molecular anions (carbanions). The detection of cations with mass only up to 350 amu reflects the limitation of the IBS instrument (Young et al., 2004) itself. In analogy to the growth of negative ions, "massive" cationic macromolecules are expected and are most likely the haze precursors. These highly unexpected findings -i.e., the detection of carbocations (Olah 1972, 1995) and carbanions (Cram 1965)- have made a drastic impact on the understanding of Titan's atmospheric chemistry. These observations by Cassini instruments thus placed emphasis on important classes of elementary organic reactions (see below) that have implications on the chemical synthesis and pathways: the molecular growth starts in the upper atmosphere rather than at lower altitude (Ali et al. 2013).

In a recent paper Lavvas et al. (2013) studied aerosol growth in Titan's ionosphere. Although these authors noted the importance of ion-neutral processes, the chemistry of carbocations and their role on the significance of macromolecular growth was not identified. Nor there is any detailed discussion on the chemistry of anions on Titan from small to larger sizes. Nevertheless, negative ion chemistry in Titan's upper atmosphere has been presented by Vuitton et al. (2009b) to explain observations of three low mass anion peaks in the CAPS-ELS spectrum (Coates et al. 2007, 2009). These three low mass peaks are attributed by Vuitton et al. (2009b) to $\mathrm{CN}-, \mathrm{C} 3 \mathrm{~N}-/ \mathrm{C} 4 \mathrm{H}$ - and $\mathrm{C} 5 \mathrm{~N}$-. The reader is referred to section 4 for details on carbanion chemistry on Titan.

In this paper the carbocationic chemistry (Olah 1972, 1995) in Titan's atmosphere is addressed: A chemical pathway to polycyclic aromatic hydrocarbons (PAHs) and heterocyclic molecules where one or more of the carbon atoms are replaced by some other atoms, like nitrogen. We propose that electron recombination processes of various closed-shell cyclic-aromatic carbocations lead to the production of neutral precursors to haze. Furthermore, we suggest that the complex molecular anions of very high mass observed by CAPS-ELS (Coates et al., 2007, 2009; Waite et al., 2007) are then formed via subsequent electron attachment kinetics to the corresponding neutrals. Though the chemistry of molecular anions in space is less well studied (Herbst and Millar 2008; Larsson et al. 2012), we use an apparent antipodal relation between carbanions and carbonium ions to demonstrate that the growth of molecular anions observed by CAPS-ELS (Coates et al. 2007; Waite et al. 2007) is closely linked to the growth of cations observed by INMS and CAPS-IBS (Waite et al. 2007, 2008, 2009; Crary et al. 2009). In a recent publication (Ali et al. 2013), the cyclopropenyl cation and its cyclic methyl derivatives are considered as the prototype for aromatic molecules in Titan's atmosphere, and these smallest Huckel rings serve to illustrate how aromaticity is involved in the chemistry in Titan's upper atmosphere. This makes for an interesting premise for complex organic chemistry, i.e., the chemistry involving extensively conjugated and aromatic molecules.

The present paper is divided into six sections including introduction. In section 2 we briefly describe the measurement techniques for the three CAPS sensor optics: the lon Mass Spectrometer (IMS), the lon Beam Spectrometer (IBS) and the Electron Spectrometer (ELS). The limitations of energy/charge measurements by CAPS sensors and the inferred ion/mass spectrum in comparison to that of the measurements by INMS (mass/charge spectrometer) will be reviewed. The measurements by CAPS sensor optics are instrumentally limited; therefore, the analysis of ion composition strongly relies on the corresponding chemistry. The section 3 reports on the observations of carbocations by CAPS-IBS and of 
carbanions by CAPS-ELS, and their analysis. In the section 3 we also identify an important class of ionmolecule reactions based on several comparisons with available experimental and theoretical studies of the reaction kinetics of closed shell ions with polar/non-polar molecules in the gas phase at low temperatures (<200 K; Ali et al. 2013; Sonnenfroh and Farrar 1986; Lopez et al. 1996; Clary 1988a; Klippenstein and Georgievskii 2008). The ion-molecule reaction scheme provides a kinetic model that allows one to explain the structure and composition of the molecules detected in Titan's thermosphere and ionosphere by the Cassini CAPS instruments. The chemistry of carbonium ions, which is at the heart of the growth of complex organic molecules in the atmosphere on Titan (Ali et al. 2013), is critically examined with emphasis on the formation, the structure and the kinetic stability of some large detected carbanions (Waite et al., 2007). In passing we do note that the kinetics of negative ion chemistry in the gas phase is much less studied at temperatures and pressures of interest to the present investigation. Carbanion chemistry is addressed in Section 4. Section 5 presents the role of carbocations and carbanions in prebiotic atmospheric chemistry on Titan. The emphasis is on the fact that complex organic chemistry in Titan's upper atmosphere may tell us a lot about abiotic chemistry in the interstellar clouds (Klemperer 2011) and in the environments of extrasolar planets. We also show that Titan's prebiotic chemistry has a possible relationship with organic synthesis in the primitive atmosphere on the early earth. Finally, in section 6 we present some future studies and concluding remarks. The overall conclusion is that at the low temperatures and highly diluted environment typical of Titan's upper atmosphere the chemistry of carbocations played a significant role in the synthesis of aliphatic and aromatic hydrocarbons, also including nitrogen-bearing organic compounds, such as heterocyclic molecules. The paper furthermore sheds light on the carbanion chemistry in Titan's ionosphere, and an antipodal relation between the carbanions and the carbonium ions is brought into focus. These charged molecules grow by organic chain reactions into the macromolecules that we identified as precursors for the formation of the nanoscale haze polymer observed on Titan at relatively high altitudes (Waite et al. 2007, 2008, 2009; Crary et al. 2009; Coates et al. 2007; Vuitton et al. 2009b).

\section{1a. Chemistry}

The chemistry itself in Titan's atmosphere is quite novel, and it presents major challenges. The fundamental question is: how do the composition, structure and reactivity of Olah carbocations evolve toward the molecular complexity on Titan? Numerous cabocations (approximately 50) have been detected by INMS with density higher than $0.1 \mathrm{~cm}^{-3}$ (Vuitton et al. 2009a; Waite et al. 2007). Among the detected cations, $\mathrm{CH}_{5}{ }^{+}$is the simplest Olah's carbocation with an unusual two-electron three-center (2e, 3c) bond structure. It is also important to point out that the INMS mass spectrum shows clearly the presence of the methane radical cation, $\mathrm{CH}_{4}{ }^{+}$(Olah and Klopman 1971). In this paper, we address the the molecular growth on the basis of the observations made by cationic and anionic mass spectrometry (IBS and ELS): we describe the chemical evolution from $\mathrm{CH}_{5}{ }^{+}$to the cyclopropenyl cation and its cyclic methyl derivatives -the Huckel's smallest three-membered rings $\left(\mathrm{C}_{3} \mathrm{H}_{3}{ }^{+}, \mathrm{C}_{4} \mathrm{H}_{5}{ }^{+}, \mathrm{C}_{5} \mathrm{H}_{7}{ }^{+}\right)$- to six-membered monocyclic protonated benzene $\left(\mathrm{C}_{6} \mathrm{H}_{7}^{+}\right)$and benzyl cation $\left(\mathrm{C}_{7} \mathrm{H}_{7}^{+}\right)$rings toward polycyclic aromatic hydrocarbons (PAHs), such as BI- and TRI- and TETRA-CYCLIC benzenoid conjugated systems. Scheme 1.0 displays a few selected polycyclic aromatic hydrocarbons in the gas phase on Titan. In this paper, we primarily focus on the mechanisms of certain classes of ion-molecule reactions (Sonnenfroh and Farrar 
1986; Lopez et al. 1996; Ali et al. 2013) that explain the formation and growth of these polyaromatic hydrocarbons PAHs starting from the most stable isomers of the various carbocations detected by INMS (Scheme 2.0).

The most stable isomers corresponding to some the compositions detected by INMS are shown in Scheme 2.0. The conformational arrangement is organized into members separated by 12 amu periodicity in carbon atoms, $C_{n}$, where $n$ runs from 1 to 7 . For illustrative purpose only, the methane radical cation, the methonium ion, the protonated forms of ethylene and acetylene, the protonated cyclopropane, the cyclopropenyl cation, the protaned form of diacetylene, the methylcyclopropenyl cation, the methylallyl cation, the dimethylcyclopropenyl cation, the dimethylallyl cation, the protonated benzene (benzenium ion), the benzyl cation and the norbornyl carbonium ion are shown. The delocalization of the cationic character over various bonds as well as the electron distribution in the molecule, collision complexes, and transition states ( $\sigma$ electrons or $\pi$ electrons) are at the heart of the chemical growth testified by the Cassini Ion Beam Spectrometer (IBS) for the carbocations and by the Cassini Plasma Spectrometer (CAPS) ELS sensor for carbanions (see the discussion in Section III). The reader is also referred to the recent paper by Ali et al. (2013) on carbocation chemistry on Titan for details.

We have broadly classified the ortho-fused and ortho- and peri-fused hydrocarbon systems shown in Scheme 1.0 into two categories: (1) polycyclic systems with an odd number of carbon atoms in the aromatic skeleton, such as perinaphthenyl radical (phenalene system) $\mathrm{C}_{13} \mathrm{H}_{9}$ and its ion $\mathrm{C}_{13} \mathrm{H}_{9}{ }^{+}$, and as the $\mathrm{C}_{17} \mathrm{H}_{11}$ radical and its ion $\mathrm{C}_{17} \mathrm{H}_{11}{ }^{+}$(anthracene peri-fused with six-membered ring); (2) polyaromatic hydrocarbon systems with an even number of carbon atoms, such as benzene $\mathrm{C}_{6} \mathrm{H}_{6}$, naphthalene $\mathrm{C}_{10} \mathrm{H}_{8}$, phenanthrene $\mathrm{C}_{14} \mathrm{H}_{10}$, pyrene $\mathrm{C}_{16} \mathrm{H}_{10}$, and chrysene $\mathrm{C}_{18} \mathrm{H}_{12}$. In these conjugated systems, one hydrogen atom can be replaced by the methylene cation $\mathrm{CH}_{2}{ }^{+}$, thus leading to $\mathrm{C}_{7} \mathrm{H}_{7}{ }^{+}, \mathrm{C}_{11} \mathrm{H}_{9}{ }^{+}, \mathrm{C}_{15} \mathrm{H}_{11}{ }^{+}, \mathrm{C}_{17} \mathrm{H}_{11}{ }^{+}$and $\mathrm{C}_{19} \mathrm{H}_{13}{ }^{+}$, respectively. In particular, the stability of $\mathrm{C}_{7} \mathrm{H}_{7}{ }^{+}$and $\mathrm{C}_{11} \mathrm{H}_{9}{ }^{+}$(deriving from the cleavage of a methyl hydrogen from toluene and methylnaphthalene, respectively; Huang and Dunbar 1990; Gotkis and Lifshitz 1993) plays an important role in the aromatic stability in Huckel rings (Hoffmann 1964a, 1964b). The delocalization of the positive charge over more bonds and the distribution of electrons in INMS detected carbocations are shown in Scheme 2.0. Not only the $\pi$-bond, but also the two electrons from the $\sigma$-bond are delocalized over three centers in a carbonium ion such as the norbornyl cation $\mathrm{C}_{7} \mathrm{H}_{11}{ }^{+}$. The influence of $2,6,10$ or more $\pi$-electrons is clearly evident in the literature of aromatic stability, but what seems to be more important in the chemistry on Titan are the penta- or tetracoordinated nonclassical incipient carbonium ions (Olah 1972, 1995). In fact, the measurements from the mass/charge spectrometer (INMS) on the Cassini Spacecraft imply a series of ion-molecule reactions (Ali et al., 2013) involving carbocations that explain the sequential growth pointed out by energy/charge (IBS and ELS). A selection of heterocyclic molecules, amino- and cyano- aromatics has also been considered and is displayed in Scheme 3.0. Shown here are pyridine $\mathrm{C}_{5} \mathrm{H}_{5} \mathrm{~N}$, pyrrole $\mathrm{C}_{4} \mathrm{H}_{4} \mathrm{NH}$, and aniline $\mathrm{C}_{6} \mathrm{H}_{5} \mathrm{NH}_{2}$. The corresponding closed-shell cations $\mathrm{C}_{5} \mathrm{H}_{4} \mathrm{~N}^{+}, \mathrm{C}_{4} \mathrm{H}_{4} \mathrm{~N}^{+}$, and $\mathrm{C}_{6} \mathrm{H}_{5} \mathrm{NH}^{+}$as well as the corresponding protonated species, $\mathrm{C}_{5} \mathrm{H}_{5} \mathrm{NH}^{+}, \mathrm{C}_{4} \mathrm{H}_{5} \mathrm{NH}^{+}$, and $\mathrm{C}_{6} \mathrm{H}_{7} \mathrm{NH}^{+}$, respectively, have been detected in the INMS mass spectrum at high altitudes in the upper atmosphere. In Scheme 3.0, BI- and TRI-CYCLIC aromatic systems containing nitrogen are displayed as well. Examples are the radical and the 
corresponding ion obtained by replacing a $\mathrm{CH}$ group with an $\mathrm{N}$ atom in phenalenyl radical, $\mathrm{C}_{12} \mathrm{H}_{8} \mathrm{~N}$ and $\mathrm{C}_{12} \mathrm{H}_{8} \mathrm{~N}^{+}$, respectively. Similarly, substituted benzopyridine (quinoline) and nitrogen-containing phenanthrene are shown in this scheme: in both systems one hydrogen atom has been replaced by the methylene cation $\mathrm{CH}_{2}{ }^{+}$, thus leading to $\mathrm{C}_{10} \mathrm{H}_{8} \mathrm{~N}^{+}$and $\mathrm{C}_{14} \mathrm{H}_{10} \mathrm{~N}^{+}$, respectively (see Scheme 3.0).

The temperature at which the various chemical reactions take place in Titan's upper atmosphere is close to $150 \mathrm{~K}$, and the pressure is also too low for three-body recombination reactions to occur. The temperature, pressure and time-scales are the three most important parameters in treating the kinetics of chemical reactions using the Transition-state theory (TST) -a standard choice in chemical literature over seventy-five years (Truhlar, Garrett, Klippenstein 1996). Its microcanonical counterpart RRKM (Rice, Ramsperger, Kassel, Marcus)-based transition state theory or the RRKM theory in its variational treatment (the transition state at the minimum of an entropy barrier along the reaction coordinate) provides the most practical working models for kinetics and dynamics (Holbrook, Pilling, and Robertson 1996; Gilbert and Smith 1990; Robinson and Holbrook 1972). In the planetary atmospheres and in the interstellar clouds, at low pressures and temperatures (that can be as low as $10 \mathrm{~K}$ ), in the absence of termolecular recombination reactions, ion-molecule (Bates and Herbst 1988; Smith 1989) and radicalradical/molecule (Brownsword et al. 1997; Vuitton et al. 2012) radiative association reactions might play a role in the synthesis of complex polyatomic species. With a few exceptions, there are no laboratory measurements of radiative lifetimes of collision complexes related to atmospheric chemistry and interstellar clouds (Gerlich and Horning 1992). Therefore, a quantitative understanding of the radiative association rate coefficients is far from being complete. Nevertheless, we are left with a choice of detailed measurements of termolecular recombination rate coefficients at low temperatures $(10-200$ K; Rowe et al. 1984) and extrapolation of data using the statistical RRKM theory from the high-pressure strong collision limit to the weak collision low-pressure limit (Holbrook, Pilling, Robertson 1996). 


\section{Measurement Techniques}

The ion and neutral compositions have been successfully measured from a combination of spectrometers on the Cassini spacecraft that allowed for masses to be derived either directly from the mass/charge ( $M / Q$ ) analysis or from the energy/charge (E/Q) analysis. The Cassini Ion and Neutral Mass Spectrometer (INMS; Waite et al. 2004) is a standard quadrupole mass spectrometer that performs a mass/charge analysis, whereas all three sensors in the Cassini Plasma Spectrometer (CAPS), i.e., the Electron Spectrometer (ELS), the Ion Beam Spectrometer (IBS), and the Ion Mass Spectrometer (IMS) involve an energy/charge analysis (Young et al. 2004). The details of this instrumentation can be found in Waite et al. 2004 and in Young et al. 2004. For reader benefit, we here report a very brief presentation of these techniques.

The CAPS sensor optics is schematically shown in Fig.1. First of all, the IMS (Young et al. 2004) in the CAPS package essentially performs an E/ $Q$ analysis in the top-hat electrostatic analyzer. After the energy selection, the mass analysis is carried out by the linear electric field (LEF) time-of-flight (TOF) technique. The basic idea is that ions after exiting the electrostatic analyzer (ESA) are post accelerated and pass through a thin carbon foil where they knock out electrons. Electrons are then accelerated downward away from the carbon foil, striking the micro channel plate (MCP) at the bottom of the IMS. This will start a signal on the MCP for the TOF measurements, whereas the positive ions leaving the foils are reflected upward in the LEF and detected on a stop MCP. The LEF time-of-flight sensor thus has a start and a stop signal to carry out time of flight measurements (Young et al. 2004). For ions, the equation of motion in a linear electric field (LEF) is the simple harmonic oscillation in a harmonic potential where the time-of-flight (half of an oscillation) is proportional to the square root of the mass (Wuest 1998). By combining two techniques the ions of selected energy by the ESA are mass analyzed by the LEF time-offlight in the IMS in CAPS package (Young et al. 2004). The CAPS-IMS measures the composition of highenergy diffuse magnetospheric plasmas and helps to characterize the energy deposition process into the ionosphere (Sittler et al. 2009, Hartle et al. 2006).

The Ion Beam Spectrometer IBS is a hemispherical electrostatic analyzer. The energy resolution $(\triangle \mathrm{E} / \mathrm{E})$ of this electrostatic analyzer is approximately $1.7 \%$ (Young et al. 1998, 2004). The orbital velocity of the Cassini spacecraft is $6 \mathrm{~km} / \mathrm{s}$. Since the temperature of ions in the cold environment typical of Titan's upper atmosphere is close to $150 \mathrm{~K}$, the ions arrive at the IBS sensor as a supersonic beam with a constant spacecraft velocity. Since the masses of ions are different, the corresponding energies are determined essentially by the spacecraft ram velocity as $E_{\text {ion }}=m_{\text {ion }} V_{s c}{ }^{2} / 2$, where $E_{\text {ion }}$ is the energy of the ionic species and $m_{i o n}$ its mass, and $V_{s c}$ the ram velocity of the spacecraft. Thus, the $E / Q$ analysis of the peaks in IBS ion energy spectrum allows us to infer the mass/charge $(M / Q)$ of the observed ion. However, the spacecraft potential, which ranges from -0.5 to $-2.0 \mathrm{~V}$, introduces an uncertainty in the ion mass number (Waite et al. 2008, 2009). The lon neutral mass spectrometer INMS measures in Titan's upper atmosphere the mass distribution up to 100 atomic mass unit (amu) with one amu mass resolving capabilities between adjacent masses. The INMS measurements are scaled to IBS resolution (Crary et al., 2009) and extended up to $350 \mathrm{amu}$, which is the maximum limit of the IBS observation. With adjustable spacecraft potential, the regular mass peak spacing of approximately 12 amu in INMS measurements 
matches very well with IBS observation and with model deconvolution in the extended mass range (Crary et al. 2009; Waite et al. 2008, 2009).

The observation of negative ions in Titan's upper atmosphere is carried out by CAPS-ELS (Coates et al. 2007; Waite et al., 2007, Vuitton et al. 2009, Sittler et al. 2009). The ELS sensor in the CAPS package (Young et al. 2004) is also a hemispherical, electrostatic top-hat analyzer, and the application principle is analogous to that of CAPS-IBS (Linder et al. 1998; Coates et al. 2007; Waite et al. 2008, 2009; Vuitton et al. 2009). In this case, the energy resolution ( $\triangle \mathrm{E} / \mathrm{E}$ ) is $16.7 \%$ (Young et al. 2004), and is comparatively poorer than that of IBS. It was originally designed to measure kinetic energy distribution of electrons in Saturn's magnetosphere. The conversion factor from the ram energy spectra to mass spectra for singly charged ions is given by $\mathrm{m}_{\mathrm{amu}}=5.32 \mathrm{E}_{\mathrm{ev}}$, with $6 \mathrm{kms}^{-1}$ flyby speed, and is used in the literature to trace masses for negative ions with the assumption that they are singly charged. The CAPS actuator moves the ELS field of view through the ram direction in Titan's ionosphere. The spikes in the ELS energy-time spectrograms are the signatures of negative ions rather than electrons (Coates et al. 2007; Waite et al. 2007; Vuitton et al. 2009) because thermal velocities of ions at $150 \mathrm{~K}$ are much smaller than the spacecraft velocity, whereas electrons are isotropic and have supra-thermal velocities and thus should be detected from any actuator position. The peaks in the spectra identified as negative ions are highly narrow and unidirectional, and thus they cannot be misidentified as electrons (Coates et al. 2007; Waite et al. 2007, 2009). Because of the very low energy resolution with respect to IBS, the mass spectrum of negatively charged ions in CAPS-ELS is structureless in higher masses, i.e., there are no distinct peaks (Coates et al. 2007; Waite et al. 2007; Sittler et al. 2009). Thus, the composition corresponding to a given mass in the high mass region cannot be identified directly from the CAPS-ELS spectrum (Vuitton et al. 2009). However, the mass group analysis based on broad structure was performed (Coates et al. 2007, 2009; Wellbrock et al. 2013). 


\section{Ion Beam Spectrometer (IBS) and Electron Spectrometer (ELS) Observations of Organic Synthesis in Titan's Upper Atmosphere: Mechanistic Interpretation of the Chemical Composition and Molecular Structure}

An important issue in Titan's chemistry is tracing a chemical route from molecular precursors, such as the nonclassical pentacoordinated methonium $\mathrm{CH}_{5}{ }^{+}$ion and the tetracoordinated methane radical cation $\mathrm{CH}_{4}{ }^{+}$(with an unusual nature of three-center two-electron-bond structure), through aliphatic and aromatic organic polymers to nanoscale haze matrix. The chemistry of protonated hydrogen cyanide $[\mathrm{HCNH}]^{+}$also plays an important role in the chemical synthetic route to $\mathrm{N}$-bearing organic macromolecules.

As mentioned in Section 2, the measurements of the mass spectrum of cations by IBS extend up to 350 amu. Since the energy resolution ( $\triangle \mathrm{E} / \mathrm{E}$ ) of IBS electrostatic analyzer is only $1.7 \%$, the resolution is not sufficient to resolve cationic masses distinctively like in the INMS, and thus a unique identification of molecular composition is difficult. In a recent paper, Crary et al. (2009) modeled the IBS mass spectrum, and in their statistical model the Cassini INMS measurements were scaled to IBS mass resolution. In this deconvoluted model of the IBS ion mass spectrum, the regular mass peak spacing of 12 amu seen in the INMS measurements is clearly reflected. This 12 amu periodicity in CAPS-IBS ion mass spectrum measurements reflects the atmospheric growth of macromolecules with significant ion densities; these molecular ions could be grouped in terms of the number $C_{n}$ of the carbon atoms contained (where $n$ runs from 1 to 28). One or more of the carbon atoms in these molecular ions can also be replaced by nitrogen. Table 1 lists a few selected cationic species measured in the INMS mass spectrum (Vuitton et al. 2009; Waite et al. 2007, 2009). In Table 2 we report the composition of selected carbocations in the high-mass group in the IBS ion mass spectrum. In a recent publication (Ali et al. 2013), an analysis of the Cassini INMS observations based on the identification of an important class of ion-molecule reactions proceeding via carbocation collision complexes reveals the existence of the cyclopropenyl cation -the smallest Huckel ring (prototype for aromaticity)- and its cyclic methyl and dimethyl cations in the chemistry of atmosphere on Titan. The ion-molecule reactions are fast at low temperatures (10-200 K) and involve the interaction of a closed-shell ion with a polar or a nonpolar molecule (see Fig 1 in Ali et al. 2013). One of the aims in this paper is to provide a scheme of a branched-chain reaction involving the similar ion-molecule kinetics of the polymerization process that explores primarily the aromaticity in the composition of high-mass group ions in the mass spectra from CAPS-IBS. Here, we demonstrate how molecular structures and reactivity of carbocations and their relevance to nonclassical carbonium ions (Olah 1972, 1995) in the thermodynamics and kinetics of chemical pathways will lead to the formation of conjugated and aromatic molecules containing primarily $\pi$-electron bridged benzonoid rings and nitrogen bearing heterocycles.

The presence of ions corresponding to the composition $\mathrm{C}_{7} \mathrm{H}_{7}{ }^{+}$in the INMS mass spectrum with enough density is extremely important for the gas-phase ionic syntheses of aromatic structures on Titan. In these ionic syntheses, it is important to follow the progression kinetics of sequential reactions of ethylene, acetylene, propylene, and methylacetylene with benzyl cation. However, not all ion-molecule reactions in the gas-phase could be studied in the laboratory toward the observation of reaction products and the measurement of their relative yields (the branching ratios). The reactions of $\mathrm{CH}_{3}{ }^{+}$with 
ethylene and acetylene are well studied and the best prototypes (Sonnenfroh and Farrar, 1986) of an important class of ion-molecule reactions involving the interactions of closed-shell ions, such as benzyl cation $\mathrm{C}_{7} \mathrm{H}_{7}{ }^{+}$, with unsaturated hydrocarbon molecules. In fact, by replacing one hydrogen atom in $\mathrm{CH}_{3}{ }^{+}$ with a phenyl group $\mathrm{C}_{7} \mathrm{H}_{7}{ }^{+}$is obtained. Quantum-chemical calculations and laboratory experiments have been carried out for mapping out the minimum energy paths from reagents to the different sets of products and their isomers in the dynamics of $\mathrm{CH}_{3}{ }^{+}$collisions with acetylene and ethylene (Lopez et al. 1996; Sonnenfroh and Farrar 1986). The measurements of product center-of-mass translational energy distributions from crossed-beam study of these reactions led to the derivation of the life time of transient collision complexes -a very important feature in the dynamics of collisions- and hence of the quantitative product branching fractions (Sonnenfroh and Farrar 1986). The theoretical and experimental studies of carbocation chemistry mentioned above along with the observation of the composition of numerous carbocations in Titan's upper atmosphere by the Cassini lon Neutral Mass Spectrometer (INMS) allowed us to definitively confirm the formation of the cyclopropenyl cation and its cyclic methyl derivatives on Titan (Ali et al. 2013). In the present work, we show that the analysis of the data set from the CAPS-IBS mass/charge spectrum of cations reveals the formation of complex aromatic structures in Titan's chemical environment based on the kinetics and dynamics of analogous reactions of $\mathrm{C}_{7} \mathrm{H}_{7}^{+}$with unsaturated hydrocarbon molecules.

Scheme 4.0 illustrates the reaction paths of the formation of the perinaphthenyl cation $\mathrm{C}_{13} \mathrm{H}_{9}{ }^{+}$from ionmolecule reactions of sequential addition of $\mathrm{C}_{2} \mathrm{H}_{4} / \mathrm{C}_{2} \mathrm{H}_{2}$ to $\mathrm{C}_{7} \mathrm{H}_{7}^{+}$. The elementary gas-phase reactions of $\mathrm{CH}_{3}{ }^{+}$with $\mathrm{C}_{2} \mathrm{H}_{4}$ and $\mathrm{C}_{2} \mathrm{H}_{2}$ provide the best explanation of the reaction mechanisms involving carbocation chemistry displayed in Scheme 4.0. The reader is therefore referred to Ali et al. (2013) where the mechanisms of reactions of closed-shell ion $\mathrm{CH}_{3}{ }^{+}$with a number of unsaturated hydrocarbons, such as ethylene and acetylene, at low temperatures $(<200 \mathrm{~K})$ and under reactive single-collision conditions are described in detail. For the sake of completeness, we briefly review these reactions before elucidating the role of the chemistry of carbocations on Titan in the synthesis of complex polycyclic aromatic hydrocarbon molecules (Scheme 4.0) and their corresponding radicals and carbanions.

The reactions of $\mathrm{CH}_{3}{ }^{+}$with both $\mathrm{C}_{2} \mathrm{H}_{4}$ and $\mathrm{C}_{2} \mathrm{H}_{2}$ involve condensation proceeding via carbocation collision complexes (Ali et al. 2013). In the case of ethylene, crossed-beam measurements confirmed that the minimum energy reaction pathway leads to the initial formation of the three-center two-electron bond in metastable corner-protonated cyclopropane $\left(\mathrm{C}_{3} \mathrm{H}_{7}{ }^{+}\right)$by an electrophilic attack of $\mathrm{CH}_{3}{ }^{+}$to the $\pi$ cloud of ethylene. The $\mathrm{C}_{3} \mathrm{H}_{7}{ }^{+}$cation then readily isomerizes by ring opening to the n-propyl cation, followed by a 1,2 hydrogen atom shift to the lowest energy sec- $\mathrm{C}_{3} \mathrm{H}_{7}{ }^{+}$structure (Hariharan et al. 1974). The sec- $\mathrm{C}_{3} \mathrm{H}_{7}{ }^{+}$ minimum structure decays to the final product, i.e., the delocalized allyl cation $\left(\mathrm{C}_{3} \mathrm{H}_{5}^{+}\right)$, through ejection of one $\mathrm{H}_{2}$ molecule (Sonnenfroh and Farrar 1986). In addition, the sec- $\mathrm{C}_{3} \mathrm{H}_{7}{ }^{+}$structure also yields $\mathrm{CH}_{4}+$ $\mathrm{C}_{2} \mathrm{H}_{3}{ }^{+}$through a hydride abstraction. A third reaction channel exists where the metastable adduct sec$\mathrm{C}_{3} \mathrm{H}_{7}{ }^{+}$forms the $\mathrm{C}_{3} \mathrm{H}_{3}{ }^{+}+2 \mathrm{H}_{2}$ condensation products. This process occurs by sequential ejection of two $\mathrm{H}_{2}$ molecules from the adduct, first forming the $\mathrm{C}_{3} \mathrm{H}_{5}{ }^{+}$intermediate that subsequently decays to $\mathrm{C}_{3} \mathrm{H}_{3}{ }^{+}$ (Sonnenfroh and Farrar 1986). $\mathrm{C}_{3} \mathrm{H}_{3}{ }^{+}$has two isomeric structures: one is the cyclopropenyl cation, cyclic$\mathrm{C}_{3} \mathrm{H}_{3}{ }^{+}$, and the other is the propargyl cation $\left[\mathrm{HCCCH}_{2}\right]^{+}$. The cyclic isomer is more stable than the linear one by $27.4 \mathrm{kcal} / \mathrm{mol}$ (Ali et al. 2013). As in the case of the reaction with ethylene, both the cyclic- $\mathrm{C}_{3} \mathrm{H}_{3}{ }^{+}$ 
and linear- $\mathrm{C}_{3} \mathrm{H}_{3}{ }^{+}$isomers are generated by the unimolecular decomposition of the collision complex $\mathrm{C}_{3} \mathrm{H}_{5}{ }^{+}$formed from the bimolecular reaction of $\mathrm{CH}_{3}{ }^{+}$with acetylene. The potential energy surface for the $\mathrm{CH}_{3}{ }^{+}+\mathrm{C}_{2} \mathrm{H}_{2}$ system is shown schematically in Fig.1 of Ali et al. (2013). Three collision complexes and nine transition states are shown in that schematic reaction-coordinate plot, where the delocalized allyl cation, $\mathrm{C}_{3} \mathrm{H}_{5}{ }^{+}$, is the global minimum. The details of the specific features of the potential energy surface and of the chemical dynamics are given in Ali et al. (2013). The overall conclusion is that, based on the crossed-beam measurements and theoretical studies of chemical dynamics proceeding over the potential energy surfaces in the reactions of $\mathrm{CH}_{3}{ }^{+}$with $\mathrm{C}_{2} \mathrm{H}_{4}$ and $\mathrm{C}_{2} \mathrm{H}_{2}$, the formation of the the cyclopropenyl cation is the most favored in the product isomer branching ratios (Ali et al. 2013). We reiterate that the temperature at which the various chemical reactions in the gas phase take place in Titan's upper atmosphere is close to $150 \mathrm{~K}$, and hence at low collision energies. At low energies, the fraction of the cyclopropenyl cation produced is significant in the acetylene reaction. In the case of ethylene system, the cyclopropenyl cation is formed exclusively at low temperatures, which is of great relevance to the chemistry of Titan's atmosphere. The main result of the paper by Ali et al. (2013) is the presence of the cyclopropenyl cation and its cyclic methyl derivatives in Titan's upper atmosphere. The Ali et al. (2013) paper underpins Titan's organic chemistry and pointed out that an understanding of molecular structures and reactivity of carbocations (detected by Cassini instruments) and their relevance to "nonclassical" carbonium ions allows for exploring aromaticity in the atmosphere of Titan and chemical pathways toward prebiological molecules.

As mentioned above, Scheme 4.0 displays reaction paths that illustrate the formation of perinaphthenyl $\mathrm{C}_{13} \mathrm{H}_{9}{ }^{+}$cation from sequential addition of ethylene to the benzyl cation. Following the reaction mechanisms pointed out in Ali et al. (2013), we can derive those leading to the formation of $\mathrm{C}_{13} \mathrm{H}_{9}{ }^{+}$. In the ion-molecule chain reactions, diverse branched products are produced sequentially through the ejection of either one or two molecules of $\mathrm{H}_{2}$. Addition of ethylene to the benzyl cation first forms an intermediate, the mono-substituted derivative of allyl cation $\left[\mathrm{CH}_{2}-\mathrm{CH}-\mathrm{CH}_{2}\right]^{+}$, where one of the hydrogen atoms of the end carbons is replaced by the benzene ring with an elimination of one $\mathrm{H}_{2}$ molecule. With the loss of another molecule of $\mathrm{H}_{2}$, this intermediate $\left[\mathrm{CH}\left(\mathrm{C}_{6} \mathrm{H}_{5}\right)-\mathrm{CH}_{-}-\mathrm{CH}_{2}\right]^{+}$may lead to the ring closure and form a branched product where the six-membered ring is bridged with five-membered ring (Scheme 4.0). Further reaction of ethylene with this intermediate yields the $\mathrm{CH}_{2}{ }^{+}$mono-substituted derivative of naphthalene in position 1 by sequential ejection of two $\mathrm{H}_{2}$ molecules via an intermediate step, as shown in Scheme 4.0. While the discussion of the partial change in the aromatic character of naphthalene due to the $\mathrm{CH}_{2}{ }^{+}$substituent is completely out of the scope of this paper, we note that the formation of the perinaphthenyl cation $\mathrm{C}_{13} \mathrm{H}_{9}{ }^{+}$then proceeds from the chain reaction of ethylene with the $\mathrm{CH}_{2}{ }^{+}$monosubstitued naphthalene intermediate through the ejection of two molecules of $\mathrm{H}_{2}$ (see Scheme 4.0).

That given above is a mechanistic interpretation of the formation of two and three ring polycyclic aromatic hydrocarbons in Titan's upper atmosphere. Although not shown in Scheme 4.0, numerous other possibilities for diverse product formation in Titan's atmosphere exist. To give an example, the addition of methyl ethylene (propene) to the benzyl cation in the very first step of an ethylene chain reaction may yield the product intermediate $\left[\mathrm{CH}\left(\mathrm{C}_{6} \mathrm{H}_{5}\right)-\mathrm{CH}-\mathrm{CH}\left(\mathrm{CH}_{3}\right)\right]^{+}$plus a $\mathrm{H}_{2}$ molecule. The sequential addition of ethylene molecules to this intermediate then involves condensation reactions (Ali et al. 
2013) and leads to the formation of stable products, such as the $\mathrm{CH}_{2}{ }^{+}$mono-substituted methyl naphthalene $\mathrm{C}_{12} \mathrm{H}_{11}{ }^{+}$(by addition of 1 ethylene) and the methyl substituent attached to perinaphthenyl cation $\mathrm{C}_{14} \mathrm{H}_{11}{ }^{+}$(by addition of 2 ethyle molecules). The reader is here referred to Scheme 5.0. We do note that single-collision conditions prevail in the upper atmosphere of Titan. It is thus tempting to ask the question whether a triple bond in reactive ortho-benzyne intermediate may exist in the formation of two- and three-ring systems in carbocation chemistry on Titan and which is the carbon-carbon bond formation dynamics at its basis. Based on the schematic minimum energy chemical reaction pathway in Ali et al. (2013), the reaction of the benzyl cation with acetylene at the temperatures typical of Titan's atmospheric chemistry forms the phenyl cyclopropenyl cation as a major product (Basu and Bose 1966). This reaction also leads to the formation of the phenyl propargyl cation, $\mathrm{C}_{6} \mathrm{H}_{5}-\mathrm{C} \equiv \mathrm{C}-\mathrm{CH} 2^{+}$, but in small proportion and in a minor channel with respect to the global intermediate phenyl allyl cation $\left[\mathrm{CH}\left(\mathrm{C}_{6} \mathrm{H}_{5}\right)-\right.$ $\left.\mathrm{CH}-\mathrm{CH}_{2}\right]^{+}$. The multiple addition of ethylene to this isomer of phenyl propargyl cation then evolves into the two and three six-membered ortho and ortho-peri bridged ring carbonium ion chemistry, respectively, but both ring systems contain a triple bond between the carbon atoms in ortho positions. Scheme 5.0 displays the ortho-fused BI-CYCLIC and ortho- and peri-fused TRI-CYCLIC systems containing methyl substitution and one triple bond between ortho carbons. In passing we note that the methylene cation $\mathrm{CH}_{2}{ }^{+}$substituent attached to aromatic hydrocarbons may affect the molecular geometry and the global aromatic character.

The position of the $\mathrm{CH}_{2}{ }^{+}$substituent in 1-methylenenaphthalene is such that multiple addition of $\mathrm{C}_{2} \mathrm{H}_{4}$ to it in a very short chain of reaction could also lead to the formation of a methylene $\mathrm{CH}_{2}{ }^{+}$substituted derivative of ortho-bridged tri-cyclic phenanthrene system in addition to the perinaphthenyl $\mathrm{C}_{13} \mathrm{H}_{9}{ }^{+}$ cation (Scheme 1.0). In other words, both peri- and otho- fused polycyclic hydrocarbons, such as phenalene (perinaphthenyl) and $\mathrm{CH}_{2}{ }^{+}$substituent attached to phenanthrene in the position 1, could be produced. These tri-cyclic hydrocarbons can further grow into polycyclic hydrocarbon macromolecules that are the precursors to the haze observed on Titan. To give an example, the tri-cyclic phenalene $\mathrm{C}_{13} \mathrm{H}_{9}{ }^{+}$cation can lead by ethylene chain reactions to either tetra-cyclic rings $\mathrm{C}_{17} \mathrm{H}_{11}{ }^{+}$(i.e., the anthracene ring is peri-fused with another six-membered ring) or pyrene (an aromatic hydrocarbon) with $\mathrm{CH}_{2}{ }^{+}$ substituent $\left(\mathrm{C}_{17} \mathrm{H}_{11}{ }^{+}\right)$. Similarly, 1-methylenephenanthrene can sequentially grow to the aromatic product formed by chrysene with a $\mathrm{CH}_{2}{ }^{+}$substituent in position $1\left(\mathrm{C}_{19} \mathrm{H}_{13}{ }^{+}\right)$and to the perianthracenyl $\mathrm{C}_{17} \mathrm{H}_{11}{ }^{+}$cation. As already mentioned in the Introduction, the fused polycyclic hydrocarbons shown in Scheme 1.0 are broadly classified into two families: (1) polycyclic systems with an odd number of carbon atoms in the aromatic skeleton (such as $\mathrm{C}_{13} \mathrm{H}_{9}{ }^{+}$and $\mathrm{C}_{17} \mathrm{H}_{11}{ }^{+}$); (2) polyaromatic hydrocarbon systems with an even number of carbon atoms (such as benzene, naphthalene, phenanthrene, pyrene, and chrysene) with one hydrogen atom replaced by the methylene cation $\mathrm{CH}_{2}{ }^{+}$(thus leading to $\mathrm{C}_{7} \mathrm{H}_{7}{ }^{+}, \mathrm{C}_{11} \mathrm{H}_{9}{ }^{+}, \mathrm{C}_{15} \mathrm{H}_{11}{ }^{+}$, $\mathrm{C}_{17} \mathrm{H}_{11}{ }^{+}$and $\mathrm{C}_{19} \mathrm{H}_{13}{ }^{+}$, respectively).

A critical question is whether Titan's upper atmosphere is also characterized by the chemistry of nitrogen-containing heterocycles. Since the nitrogen molecule $\mathrm{N}_{2}$ is the most abundant constituent (>90\%) of Titan's atmosphere, it is reasonable to account for those molecules that are obtained by replacing one or more carbon atoms in the fused polycyclic hydrocarbons discussed above. Table 3 lists the composition of nitrogen-bearing molecular ions in the INMS mass spectrum (Vuitton et al. 2009a; 
Waite et al., 2009). The most stable nitrogen-bearing carbonium ions derive from the protonation of hydrogen cyanide, alkanitriles $\left(\mathrm{CH}_{3} \mathrm{CN}, \mathrm{C}_{2} \mathrm{H}_{5} \mathrm{CN}\right)$, alkenenitriles $\left(\mathrm{CH}_{2} \mathrm{CHCN}\right)$, and alkynenitriles $\left(\mathrm{HC}_{3} \mathrm{~N}\right.$, $\mathrm{HC}_{5} \mathrm{~N}$ ). For illustrative purposes only, in Scheme 3.0 selected heterocycles, amino- and cyano- aromatics are shown. The composition of protonated pyridine $\mathrm{C}_{5} \mathrm{H}_{5} \mathrm{NH}^{+}$, protonated pyrrole $\mathrm{C}_{4} \mathrm{H}_{5} \mathrm{NH}^{+}$, and protonated aniline $\mathrm{C}_{6} \mathrm{H}_{7} \mathrm{NH}^{+}$, and that of the closed-shell cations $\mathrm{C}_{5} \mathrm{H}_{4} \mathrm{~N}^{+}, \mathrm{C}_{4} \mathrm{H}_{4} \mathrm{~N}^{+}$, and $\mathrm{C}_{6} \mathrm{H}_{5} \mathrm{NH}^{+}$have been detected by INMS mass spectrometry (Waite et al. 2004) onboard the Cassini spacecraft at higher altitudes in the upper atmosphere (Vuitton et al. 2009a). Table 4 lists the composition of the stable Ncontaining carbonium ions corresponding to the CAPS-IBS measurements with a 12 atomic mass unit periodicity. These observations indicate the presence of the imino $>\mathrm{C}=\mathrm{NH}$ character in the carbonium ion chemistry on Titan (see the following discussion). The measurements by the Cassini INMS and CAPSIBS show that the chemistry of the N-bearing hydrocarbons in Titan's upper atmosphere is quite complex and rich. Concerning the $-\mathrm{C} \equiv \mathrm{N}^{+}$- bond rearrangement in protonated nitriles and $\mathrm{N}$-alkylnitrilium ions, the laboratory studies of the rates of isomerization kinetics of the imino functional group $>\mathrm{C}=\mathrm{N}$ $H(R)$ in carbonium ion chemistry in the gas-phase at relevant low temperatures are immensely important in Titan's prebiotic chemistry.

Protonated acrylonitrile has two resonance structures: $\left[\mathrm{CH}_{2}=\mathrm{CH}-\mathrm{C} \equiv \mathrm{N}^{+}-\mathrm{H}\right]$ and $\left[\mathrm{CH}^{+}-\mathrm{CH}=\mathrm{C}=\mathrm{N}-\mathrm{H}\right]$. The pioneering laboratory proton magnetic resonance $\mathrm{pmr}$ measurements by Olah's research group for protonated acrylonitrile in solution pointed out the importance of the second resonance structure (Olah and Kiovsky 1968). Concerning the iminocarbonium ion character, $-C E N^{+}$- should give rise to two isomeric structures, but Olah's studies of protonated forms of various nitrile compounds and $\mathrm{N}$ alkylnitrilium ions suggest that in all cases they appear to have only one linear isomer configuration involving the $-\mathrm{C} \equiv \mathrm{N}^{+}$- bond. Except some theoretical works of protonated hydrogen cyanide (Petrie 2001), there are no detailed studies or laboratory measurements in the gas phase concerning the iminocarbonium ion character of the $-\mathrm{C} \equiv \mathrm{N}^{+}$- bond and the isomeric rearrangement process in alkylnitriles, alkenenitriles, and alkynenitriles at temperatures as low as $10 \mathrm{~K}$ (temperatures that are relevant for Titan's atmosphere and interstellar clouds). Hydrogen isocyanide (HNC) has been detected in Titan's atmosphere for the first time (Moreno et al. 2011) using the heterodyne instrument on board the Herschel space observatory. It has been proposed that dissociative electron recombination of $\mathrm{HCNH}^{+}$ and other heavier nitrile ions at high altitude in Titan's upper atmosphere is most likely the route to the production of HNC (Moreno et al. 2011; Petrie 2001). Measurements of dissociative electron recombination rates of nitrile ions with the thermal electrons at low characteristic temperatures are still uncertain.

The reaction of the $\mathrm{C}_{6} \mathrm{H}_{5} \mathrm{NH}^{+}$ion (abundant in Titan's atmosphere; Vuitton et al. 2009a) with unsaturated hydrocarbons, such as ethylene and propene, may bring the imino $>\mathrm{C}=\mathrm{N}-\mathrm{R}$ character in the carbocationic chemistry of Titan's upper atmosphere through $\mathrm{CN}$ bond rearrangement. In Scheme 6.0 we show the progression of the chain reaction of ethylene with $\mathrm{C}_{6} \mathrm{H}_{5} \mathrm{NH}^{+}$to elucidate the formation mechanism of heteroaromatic systems, such as the $\mathrm{CH}_{2}{ }^{+}$mono-substituted derivative of quinoline (the position of the substituent in the heterocycle is 4 ) and the phenalene cation where a $\mathrm{CH}$ group is replaced by an $\mathrm{N}$ atom. The addition of $\mathrm{C}_{2} \mathrm{H}_{4}$ to $\mathrm{C}_{6} \mathrm{H}_{5} \mathrm{NH}^{+}$first forms the resonance intermediate $\left[\mathrm{CH}_{2}{ }^{+}-\mathrm{CH}=\mathrm{N}-\mathrm{C}_{6} \mathrm{H}_{5}\right]$ through the ejection of one molecule of $\mathrm{H}_{2}$. This stable intermediate may lead to a ring closure with the loss of 
another hydrogen molecule and thus form a branched product where the benzene ring is fused with the five-membered ring containing imino functional group (Scheme 6.0). Further ethylene addition to this intermediate $\left[\mathrm{CH}_{2}{ }^{+}-\mathrm{CH}=\mathrm{N}-\mathrm{C}_{6} \mathrm{H}_{5}\right]$ then yields the $\mathrm{CH}_{2}{ }^{+}$mono-substituted derivative (in position 4) of benzopyridine by sequential ejection of two $\mathrm{H}_{2}$ molecules via an intermediate that presents the iminocarbonium ion character, as shown in Scheme 6.0. The formation of the $\mathrm{N}$-containing perinaphthenyl (phenalene) cation $\mathrm{C}_{12} \mathrm{H}_{8} \mathrm{~N}^{+}$then proceeds from the chain reaction of ethylene with the $\mathrm{CH}_{2}{ }^{+}$-quinoline stable intermediate through the sequential ejection of two molecules of $\mathrm{H}_{2}$. See Scheme 6.0. The position of the $\mathrm{CH}_{2}{ }^{+}$substituent in quinoline is such that multiple addition of $\mathrm{C}_{2} \mathrm{H}_{4}$ to it in a chain reaction could also yield the methylene $\mathrm{CH}_{2}{ }^{+}$substituted derivative of the ortho-bridged tri-cyclic phenanthrene system where a $\mathrm{CH}$ group is replaced by an $\mathrm{N}$ atom (the composition and molecular structure of $\mathrm{C}_{14} \mathrm{H}_{10} \mathrm{~N}^{+}$is shown in Scheme 3.0). Although not shown in Scheme 6.0, the methyl derivative of heteroaromatic systems depicted in Scheme 5.0 may also emerge in Titan's upper atmosphere. To give an example, the addition of propene to $\mathrm{C}_{6} \mathrm{H}_{5} \mathrm{NH}^{+}$in the very first step of the ethylene chain reaction described above may yield the resonance structure $\left[\mathrm{CH}_{3} \mathrm{CH}^{+}-\mathrm{CH}=\mathrm{N}-\mathrm{C}_{6} \mathrm{H}_{5}\right]$ and $\mathrm{H}_{2}$. The sequential addition of ethylene to this resonance intermediate then evolves to the methyl derivative of heteroaromatics through the dynamics of carbon-carbon bond formation in carbonium ion chemistry (Ali et al. 2013).

In passing we note that the chemistry involving carbon chain molecules, such as polyacetylenes and cyanopolyynes (species observed in Titan's upper atmosphere), can lead to the growth of these species by reaction with other neutral species (Smith and Rowe 2000; Smith 2002, 2006). The laboratory measurements by means of the CRESU (Cinetique de Reaction en Ecoulement Supersonique Uniforme) technique (Rowe et al. 1984; Dupeyrat et al. 1985) have demonstrated that many radicals, such as CN and $\mathrm{C}_{2} \mathrm{H}$, react rapidly with simple alkenes and alkynes at the low temperatures typical of Titan's upper atmosphere and interstellar clouds. The corresponding reactions with polyacetylenes containing $2 n$ carbon atoms lead to the following addition reaction:

$$
\begin{aligned}
& \mathrm{C}_{2} \mathrm{H}+\mathrm{H}(\mathrm{C})_{2 n} \mathrm{H} \rightarrow \mathrm{H}(\mathrm{C})_{2 n+2} \mathrm{H}+\mathrm{H} \\
& \mathrm{CN}+\mathrm{H}(\mathrm{C})_{2 n} \mathrm{H} \rightarrow \mathrm{H}(\mathrm{C})_{2 n} \mathrm{CN}+\mathrm{H}
\end{aligned}
$$

At temperatures between 10 and $298 \mathrm{~K}$, these reactions occur essentially at the collision capture rate. The CRESU measurements of the temperature dependence of the rate constants for such radicalmolecule reactions clearly indicate that as the temperature $\mathrm{T}$ is lowered down to $10 \mathrm{~K}$, the thermal rate constant $\mathrm{k}(\mathrm{t})$ generally increases. The rapid increase of the rate constant with the temperature decrease demonstrates that the Arrhenius expression and its implication (i.e., that the activation energy reflects energy barrier between reagents and products) no longer hold (Smith and Rowe 2000): the chemistry of such neutral-neutral reactions is thus non-Arrhenius.

\section{Carbanion Chemistry on Titan}

The discovery of molecular anions in space is rather recent, and one of the most important findings in astrochemistry and chemistry of planets (McCarthy et al. 2006; Agundez et al. 2010; Herbst and Millar 
2008; Coates et al. 2007; Waite et al. 2007). Before this discovery, it was indeed proposed the presence of anions in interstellar clouds, and it was also rather clear that the main reason for the missing observation in space was the lack of accurate spectroscopic data for negatively charged ions (Cazzoli and Puzzarini 2006). Before presenting an analysis of the chemistry of negative ions observed by the Cassini CAPS electron spectrometer (ELS) (Coates et al. 2007; Waite et al. 2007), we first discuss the recent detection by radiotelescopes and their formation kinetics in the interstellar medium as well, as it bears a direct relationship with the carbanion chemistry on Titan.

The laboratory rotational spectroscopic measurements of a number of carbon chain anions by Thaddeus research group at high spectral resolution by Fourier transform microwave spectroscopy first (Thaddeus et al. 2008; Gupta et al. 2007; McCarthy and Thaddeus 2008, and references therein; Gottileb et al. 2007), and then subsequent radio search resulted in the discovery of $\mathrm{C}_{6} \mathrm{H}^{-}$and $\mathrm{C}_{8} \mathrm{H}^{-}$in the dense molecular cloud TMC-1 (McCarthy et al. 2006; Brunken et al. 2007; Millar et al. 2007), in the detection of $\mathrm{CN}^{-}, \mathrm{C}_{4} \mathrm{H}^{-}, \mathrm{C}_{6} \mathrm{H}^{-}$, and $\mathrm{C}_{8} \mathrm{H}^{-}$in the carbon-rich circumstellar envelope IRC+10216 (Agundez et al. 2010; McCarthy et al. 2006; Remijan et al. 2007; Cernicharo et al. 2007), and in the detection of $\mathrm{C}_{6} \mathrm{H}^{-}$in the low mass star-forming region of L1527 (Sakai et al. 2007; Sakai et al. 2008). After these detections, the key question to address is their formation kinetics (Herbst and Osamura 2008), and theoretical models for the interstellar chemistry (Herbst 2001, 2005; Smith 2002) needed to be revised to provide an explanation of the observed molecular abundances. Long time ago, Herbst suggested (Herbst 1981) that molecular anions could be formed in space via radiative electron attachment. The dissociative electron attachment is a process where an electron attaches to the neutral while a chemical bond is broken, for example:

$$
\mathrm{e}+\mathrm{C}_{2} \mathrm{H}_{2} \rightarrow \mathrm{C}_{2} \mathrm{H}^{-}+\mathrm{H}
$$

In most cases, the dissociative attachment is an endothermic process, since the binding energy of an electron to a neutral, i.e., the electron affinity, is generally smaller in energy than the bond energy in a chemical bond. In the case of the example above, the C-H bond energy in acetylene is $5.7 \mathrm{eV}$ (Ervin et al. 1990) and is greater than the electron affinity (Taylor et al. 1998) of $\mathrm{C}_{2} \mathrm{H}$, i.e., $\sim 3.0 \mathrm{eV}$. The electron temperature $T_{e}$ is thermal at the low temperatures typical of the interstellar clouds. Therefore, the dissociative electron attachment is generally a non-viable route for negative ion formation. The exothermic dissociative attachment at low temperatures in interstellar clouds has been however proposed (Petrie 1996; Petrie and Herbst 1997) for the formation of $\mathrm{CN}^{-}$from $\mathrm{MgNC}$ and $\mathrm{CCCN}^{-}$from the HNCCC isomer of cyanoacetylene:

$$
\begin{aligned}
& \mathrm{e}+\mathrm{MgNC} \rightarrow \mathrm{CN}^{-}+\mathrm{Mg} \\
& \mathrm{e}+\mathrm{HNCCC}^{\rightarrow} \mathrm{CCCN}^{-}+\mathrm{H}
\end{aligned}
$$

Our understanding of the radiative attachment process is at a rudimentary level. The attachment of an electron to a molecule or radical species occurs in two elementary steps as follows:

$$
\mathrm{R}+\mathrm{e} \leftrightarrows\left(\mathrm{R}^{-}\right)^{*} \rightarrow \mathrm{R}^{-}+\mathrm{hv}(6)
$$


First, the formation of a collision complex $\left(\mathrm{R}^{-}\right)^{*}$ via a free electron capture occurs with a rate constant designated as $k_{1}$. The second step is the radiative stabilization of the complex $\left(R^{-}\right)^{*}$ to the ground state of the $\mathrm{R}^{-}$anion with a rate described by $\mathrm{k}_{\mathrm{r}}$. This process may compete with the autodetachment, i.e., the reverse process of electron capture with a rate constant $\mathrm{k}_{-1}$. It is noted that the process occurs between a free electron and a neutral and thus the threshold for the detachment from the anion ground state is the electron affinity. If one accepts the statistical phase-space theory of chemical kinetics (Herbst and Osamura 2008), one would argue that after the formation of a "collision complex", the subsequent redistribution of the energy among its rovibrational states in all accessible electronic states with restrictions on the electron spin proceeds at some finite rate and may be complete during the typical lifetime of the complex. Usually, the anion ground state dominates, since it has the maximum density of quantum states at the initial energy of the formation of complex. If this process of redistribution is slow because of limited rotational and vibrational degrees of freedom available in the complex, this would most likely loose an electron via autodetachment before being stabilized by the radiative transition. As expected, the rate coefficient for the detachment of an electron is inversely proportional to the density of the vibrational quantum states of the anion $\mathrm{C}_{n} \mathrm{H}^{-}(n=2-8)$ in its ground electronic state, and because of the "microscopic reversibility" in equation (6), the anion formation in cold environments is also a matter of the lifetime of the transient negative ion against autodetachment versus the lifetime against the radiative relaxation process (Herbst and Osamura 2008). It is important to note that electron dipolebound states exist for a class of neutrals that have sufficiently high dipole moments (greater than 2.5 Debye; Guthe et al. 2001). Recent laboratory photodetachment spectroscopic studies showed that these dipole-bound excited states could play a significant role on radiative thermal electron attachment processes (the reader is referred to Fig.4 of Guthe et al. (2001)). These dipole-bound states with large electric dipole moments lie slightly below the ground state of the neutral species, with rovibrationally excited levels above the electron dissociation lower limit in the continuum of the anion. Such excited rovibrational levels in the anion continuum are termed as Feshbach states (Guthe et al. 2001; Clary 1988). Laboratory electron photodetachment spectroscopic studies also demonstrated that the lifetimes of rovibrational Feshbach states could be significantly long and thus the radiative decay channels at low electron temperatures can compete efficiently with the autodetachment process on the formation of negative ions (Guthe et al. 2001; Lykke et al. 1987; Yokoyama et al. 1996a; Yokoyama et al. 1996b). Herbst and Osamura (2008) calculated the rate coefficients for the radiative attachment reactions between the $\mathrm{C}_{n} \mathrm{H}(n=2-8)$ radicals and electron using the "phase-space" theory with the additional assumption that these dipole-bound states could be the "doorway" states for the radiative attachment process. If we assume that the complex relaxes very fast to its ground electronic state, this leads to the following simple expression for $\mathrm{k}_{-1}$ (Herbst and Osamura 2008):

$$
\mathrm{k}_{-1}=\mathrm{c} / \rho
$$

where $\mathrm{c}$ is the speed of light $\left(\mathrm{cm} \mathrm{s}^{-1}\right)$ and $\rho$ is the density of vibrational states of the complex $\left(\left[\mathrm{cm}^{-1}\right]^{-1}\right)$ at an energy approximately equal to the electron affinity. If we apply the steady-state assumption to equation (6), the overall rate coefficient for the electron attachment $K_{\text {att }}$ is given by the following expression:

$$
K_{\text {att }}=\left(k_{1} k_{r}\right) /\left(k_{r}+k_{-1}\right)(8)
$$


If the density of vibrational states is sufficiently large such that $\mathrm{k}_{-1}<\mathrm{k}_{\mathrm{r}}$, the overall radiative attachment $\mathrm{K}_{\text {att }}$ rate coefficient is approximately given by $\mathrm{k}_{1}$. In the frame of the phase-space theory, the radiative electron attachment rate coefficient is given by (Petrie and Herbst 1997; Herbst and Osamura 2008):

$$
\mathrm{k}_{1}=\mathrm{h}^{2} \mathrm{G}\left(2 \pi /\left(\mathrm{m}_{\mathrm{e}}{ }^{3} \mathrm{k}_{\mathrm{B}} \mathrm{T}\right)\right)^{1 / 2} \approx 4.98 \times 10^{-7} \mathrm{G}(\mathrm{T} / 300)^{-1 / 2}(9)
$$

where $\mathrm{G}$ is the ratio of the ground-state electronic degeneracy of the anion to the product of those of the reactants. We emphasize that the temperature dependent radiative electron attachment thermal rate coefficients have not been measured against the calculated rate constants from simple phase-space theory. According to this theory (Herbst and Osamura 2008), the radiative attachment rates for the $\mathrm{C}_{n} \mathrm{H}$ $(n=2-8)$ radicals to electrons increase in efficiency with the size of the radical. For $n \geq 6$, the rate coefficients lie at the collisional limit, i.e., almost every collision leads to the electron attachment.

Unlike the radio observations of negative ions in interstellar space, detection of molecular anions in Titan's upper atmosphere is carried out by the Cassini CAPS-ELS spectrometer (see section 2). The dominance of negative ions in Titan's upper atmosphere was not anticipated in the pre-Cassini period, and the anions are neither taken into account in atmospheric chemical models. The electron spectrometer ELS was originally designed to measure the kinetic energy distribution of hot electrons for plasma applications (Young et al. 2004), and was not meant to provide any identification of the composition of masses of molecular anions. But the measurements and analysis of the energy-time spectrograms by ELS at various altitudes showed peaks in the spectra that are far too narrow to be misidentified as isotropic hot electrons (Coates et al. 2007). The conversion factor from ram energy spectra to mass spectra for singly charged ions is $\mathrm{m}_{\mathrm{amu}}=5.32 \mathrm{E}_{\mathrm{ev}}$, and is used in the literature to trace masses for negative ions with an assumption that they are singly charged (Coates et al. 2007). Since the energy resolution ( $\triangle E$ /E) of CAPS-ELS is only $16.7 \%$ (Young et al., 2004), the mass resolving capability of the instrument ELS is too poor for a unique identification of the composition corresponding to masses in the ELS spectrum, and the analysis is model dependent (Coates et al. 2007; Vuitton et al. 2009b). Moreover, the spacecraft potential further introduces an uncertainty in the determination of the masses of anions.

A truly astonishing part in the discovery of negative ions in Titan's upper atmosphere is that the ELS spectrum extends to masses up to $13,800 \mathrm{amu} / \mathrm{q}$ (Coates et al. 2007, 2009). This means that the formation of the haze discovered earlier at lower altitudes on Titan starts in its upper atmosphere. Our interest is in the identification of the composition in the intermediate region of mass spectrum, i.e., between simple molecular anions at low mass (Vuitton et al. 2009b, Coates et al. 2007) and negatively charged particles at very large mass. This intermediate region certainly involves the negatively charged complex organic macromolecules - the carbanions. CAPS-ELS pointed out that organic molecules with size distribution of at least several hundreds of amu are synthesized in Titan's upper atmosphere. The question is then: is indeed a very large molecule (polymer) with a mass of 13,800 amu produced or does it correspond to an aerosol where the macromolecules are held together by weak polarization forces? It is very unlikely that such question could be answered by the current instruments on board the Cassini spacecraft. The first step toward the answer to this question is tracing a chemical route from simple molecules to structured conjugated and aromatic polymers and organic macromolecules in Titan's upper 
atmosphere. This is a daunting task that in turn requires to understand reaction kinetics and mechanism in carbocation and carbanion chemistry of hydrocarbons and $\mathrm{N}$-bearing molecules.

The CAPS negative ion spectrum shows two distinct ion peaks at $22 \pm 4$ and $44 \pm 8$ amu/q with a possible third peak at $82 \pm 14 \mathrm{amu} / \mathrm{q}$ (Vuitton et al. 2009b). The most recent negative ion chemistry model attributes these three low mass peaks in the unresolved CAPS-ELS broad mass spectrum to $\mathrm{CN}^{-}, \mathrm{C}_{3} \mathrm{~N}^{-}$ $/ \mathrm{C}_{4} \mathrm{H}^{-}$and $\mathrm{C}_{5} \mathrm{~N}^{-}$, respectively (Vuitton et al. 2009b). In Vuitton et al. (2009) it was conjectured that dissociative electron attachment to the neutral molecule $\mathrm{HCN}$ by suprathermal electrons through the reaction e $+\mathrm{HCN} \rightarrow \mathrm{CN}^{-}+\mathrm{H}$ initiates the formation of negative ions (see discussion below). According to this model, the negative charge is then transferred to more acidic molecules, such as $\mathrm{HC}_{3} \mathrm{~N}, \mathrm{HC}_{5} \mathrm{~N}$ or $\mathrm{C}_{4} \mathrm{H}_{2}$, via proton transfer reactions. An example is provided by the following reactions

$$
\begin{aligned}
& \mathrm{CN}^{-}+\mathrm{HC}_{3} \mathrm{~N} \rightarrow \mathrm{C}_{3} \mathrm{~N}^{-}+\mathrm{HCN} \\
& \mathrm{CN}^{-}+\mathrm{HC}_{5} \mathrm{~N} \rightarrow \mathrm{C}_{5} \mathrm{~N}^{-}+\mathrm{HCN}
\end{aligned}
$$

These proton transfer reactions belong to a class of reactions usually termed acid-base type:

$$
\mathrm{AH}+\mathrm{B}^{-} \rightarrow \mathrm{BH}+\mathrm{A}^{-}
$$

The studies of the exothermic proton transfer from an acid $\mathrm{AH}$ to a strong base $\mathrm{B}^{-}$in the gas phase at temperatures of relevance to this study, i.e., between 10 and $200 \mathrm{~K}$, are either highly limited or not available at all. The most recent kinetic studies at room temperature of the reaction of the cyanide anion $\mathrm{CN}^{-}$with cyanoacetylene, $\mathrm{HC}_{3} \mathrm{~N}$, have been performed (Carles et al. 2011) using the Rennes Flowing Afterglow Langmuir Probe-Mass Spectrometer, FALP-MS (Rowe et al. 1995). These studies indicate that the rate constant for the reaction (10) is $\mathrm{k}=4.8 \times 10^{-9} \mathrm{~cm}^{3} / \mathrm{s}$ with an uncertainty of $30 \%$. In passing we note that it might be interesting to experimentally investigate this reaction at lower temperatures using the CRESU technique (Rowe et al. 1984; Dupeyrat et al. 1985). Measurements of the temperature dependence of rate constants for this reaction might show a rapid increase of collisional rate constant by decreasing the temperature. In most cases, the data pertaining to specific reactions used in the model of anion chemistry on Titan are not measured in the laboratory; they are either derived from theory or from comparative studies of similar chemical reactions (Vuitton et al. 2009b).

The electron temperature $T_{e}$ plays a crucial role in the kinetics of various electron attachment processes. The kinetic energy distribution of electrons in the spectrum measured by ELS is variable, and dominated by a photoelectron peak at a few electron volts in presence of sunlight (Vuitton et al. 2009b; Waite et al. 2009). In dark, the characteristic equilibrium $T_{e}$ could be taken as $\sim 1,000 \mathrm{~K}$. If indeed the electrons are thermally equilibrated with the ambient ions, the characteristic electron temperature $T_{\mathrm{e}}$ should be taken as $\sim 150 \mathrm{~K}$ (Waite et al. 2007, 2009). From equation (9), we note that the radiative attachment rate coefficient is inversely proportional to the square root of the temperature. At temperatures as low as $\sim 150 \mathrm{~K}$, the radiative association between the radicals, such as $\mathrm{C}_{2 n} \mathrm{H}(\mathrm{n}=1-4)$, and electrons may dominate over other processes, such as endothermic dissociative attachment and proton transfer reactions, in model calculations of negative ion chemistry in Titan's ionosphere. Moreover, in the phasespace theory (Herbst and Osamura 2008) a strong coupling between the ground and any excited anion 
electronic state with the same spin exists. The theory indicates that the radiative attachment increases in efficiency with the size of the radical. For $n \geq 3$, the rate coefficients lie at the collisional limit, i.e., every collision between the radical and electron leads to an electron attachment. The potential energy surfaces for the dissociative attachment of unusual isomers of $\mathrm{H}_{2} \mathrm{C}_{2 n}(n=2-4)$ have been calculated (Herbst and Osamura 2008). The features of the potential energy surfaces indicate that these processes also lead to the synthesis of the $\mathrm{C}_{2 n} \mathrm{H}^{-}$anions. It appears that the process of exothermic dissociative electron attachment of carbenes must be included in the atmospheric model of anion chemistry on Titan. On the other hand, the negatively charged organic macromolecules (Coates et al. 2007) in the intermediate mass region of ELS spectrogram have not been investigated yet in Titan's ionospheric model (Vuitton et al., 2009).

The observation of macromolecular carbanions by CAPS-ELS does not necessarily mean that the growth in Titan's upper atmosphere proceeds by anion chemistry (Ali et al. 2010). We only stated that if INMS measurements of carbocations between 1 and 100 amu are scaled to IBS resolution, the extension of INMS mass range up to $200 \mathrm{amu}$ is feasible, because this fits well with the periodicity of the mass peaks in IBS measurements (see Fig. 2 in Crary et al. 2009). The approximate 12 amu periodicity (i.e., the mass peak spacing in INMS measurements) is clearly reflected in the deconvolution model in the extended mass range (Waite et al. 2008). In an earlier paper (Ali et al. 2013), we presented an analysis of INMS observations based on molecular structures and reactivity of carbocations. Underpinning Titan's organic chemistry, the analysis carried out in that paper suggests that the synthesis of complex organic molecules in Titan's atmosphere proceeds through Olah's non-classical carbocationic chemistry (Olah $1972,1995)$. In this paper, we extend our analysis of composition and molecular structures to the wider mass range covered by the IBS mass spectrum, and this analysis is also based on the dynamics of carboncarbon bond formation in carbonium (see Fig.1 in Ali et al. 2013). The presence of a periodicity in the mass peak spacing in the INMS mass spectrum is so evident in IBS measurements (Crary et al. 2009; Waite et al. 2008) that it implies the presence of carbocations and their role in organic synthesis of macromolecules. The basic theme of the earlier paper (Ali et al. 2013) was actually the presence of the three-membered Huckel aromatic rings- cyclopropenyl cation and its cyclic methyl derivatives in Titan's upper atmosphere. Here, we suggest that these aromatic rings would grow to fused six-membered polycyclic hydrocarbons, such as $\mathrm{CH}_{2}{ }^{+}$substituted derivatives of ortho-bridged bi-cyclic and tri-cyclic rings, peri-bridged tri-cyclic ring perinaphthenyl cation $\mathrm{C}_{13} \mathrm{H}_{9}{ }^{+}$, including heterocycles where a $\mathrm{CH}$ group in the polycyclic hydrocarbons is replaced by an $\mathrm{N}$ atom. These rings could chemically evolve further into the complex macromolecules. We propose that unidentified anions of macromolecules in the intermediate region of CAPS-ELS mass spectrum are formed by free electron attachment to open-shell neutrals after a long series of chemical processes involving the chemistry of carbonium ions first. The neutrals with an odd number of electrons could be formed in the ionosphere by electron recombination to macromolecular positive ions.

We conclude this section with an illustrative example. We present the determination of the temperature dependence of electron attachment to molecular complexes by radiative stabilization using the perinaphthenyl anion $\mathrm{C}_{13} \mathrm{H}_{9}{ }^{-}$as an example. The electron affinities (Wetzel and Brauman 1987; Simons and Jordan 1987) of fused polycyclic hydrocarbons are of considerable interest (Rienstra-Kiracofe et al. 
2001; Gygax, et al. 1979; Crocker et al. 1993; Schiedt and Weinkauf 1997a, 1997b). The measured adiabatic electron affinity is $1.07 \pm 0.1 \mathrm{eV}$ for the perinaphthenyl radical and was obtained from threshold photodetachment experiment (Gygax et al. 1979). As mentioned above, the process takes place between a free electron and a neutral species and thus above the threshold for detachment from the anion ground state. The autodetachment rate $\left(\mathrm{k}_{-}\right)$is inversely proportional to the density of vibrational states of the complex $\left(\left[\mathrm{cm}^{-1}\right]^{-1}\right)$ at an energy approximately equal to the electron affinity, provided that there is a strong coupling between the vibrational structure of the complex resonant states and the ground state of the anion (Herbst and Osamura 2008). Because of the large vibrational state density of the ground state of anions with very large electron ionization potentials, we expect that $\mathrm{k}_{-1}$ is much smaller than infrared radiative stabilization rate $\mathrm{k}_{\mathrm{r}}$ of equation (8). This suggests that at the characteristic electron temperature in Titan's upper atmosphere $\left(\mathrm{T}_{\mathrm{e}} \sim 150 \mathrm{~K}\right)$, anions of macromolecules can be produced via radiative electron attachment mechanisms. In 1948, Wigner developed a generalized theory according to which the cross section $\sigma$ as for the photodetachment process (Gygax et al. 1979) near threshold depends on the energy $\Delta E$ above threshold as:

$$
\sigma \propto(\Delta \mathrm{E})^{1+1 / 2}
$$

where $I$ is the lowest angular momentum of the product state. Thus, the higher the lowest angular momentum of the continuum state is, the more slowly the cross section increases above threshold. To test Wigner's theory on electron capture of molecules (the reverse process of photodetachment), i.e., to test whether the capture follows s-wave law or p-wave scattering, measurements of the kinetic rates for electron attachment processes using the CRESU technique (Moustefaoui et al. 1998) with thermalized electrons in the temperature ranges between 10 and $200 \mathrm{~K}$ are suggested. Though the negative ion chemistry at low temperatures $(10-200 \mathrm{~K})$ in the gas phase is a less developed field, to investigate the anions detected by CAPS-ELS, a very simple approach of an apparent antipodal relation between carbanions and carbonium ions in organic chemistry could be brought in CAPS and INMS combined observations. In view of elucidating the role of ion-molecule reactions in the growth of macromolecules, astronomical searches of cations and anions in the infrared (Bauschlicher and Bakes 2000) and millimeter region (McCarthy et al. 2006) should be pursued in Titan's atmosphere. In the frame of the example given above, the astronomical detection of both the perinaphthenyl cation $\mathrm{C}_{13} \mathrm{H}_{9}{ }^{+}$and its corresponding anion $\mathrm{C}_{13} \mathrm{H}_{9}$ is required. For these reasons, in the second part of this series of papers the spectroscopic characterization of some key aromatic ionic species is provided. To summarize, we propose that open-shell neutrals with odd number of electrons are produced in Titan's upper atmosphere by the recombination kinetics of low energy electrons with the many carbocations available. These radical species undergo subsequently radiative electron attachment reactions with an unpaired electron to produce corresponding anions. 


\section{Prebiotic Chemistry on Titan}

One of the principal aims of prebiotic chemistry is to answer to the following questions: How did the solar system begin, how did it evolve to the present stage, and how did the life originate on earth (Smith, Cockell, and Leach 2013)? An answer to this question is perhaps intimately linked with the chemistry in the outer solar system, which in turn might provide clues to work backwards to reveal the physical and chemical conditions prevailing in the molecular cloud collapse phase from which our solar system planets were formed. The organic chemistry on Titan starts in its upper atmosphere in the 1000$1300 \mathrm{~km}$ altitude region. The discovery of both carbocations (Vuitton et al. 2009a; Waite et al. 2007, 2009) and carbanions (Coates et al. 2007) in Titan's upper atmosphere by instruments onboard the Cassini Spacecraft (Waite et al. 2004; Young et al. 2004) is truly amazing. No other planets or their satellites in our solar system have been found to bear the level of chemical complexity that we observe on Titan: The prebiotic inventory in Titan's upper atmosphere, the macromolecules formation and assembling in a haze layer, the precipitation and sedimentation of complex organics on its surface, and the organic catalysis "on liquid" in lakes on Titan. The question that arises is then: Had this sequence of endogenous steps been followed in the primitive atmosphere of earth and delivered prebiotic compounds to the terrestrial oceans? Titan's atmosphere is relatively poor of oxygen compared to terrestrial planets, but the organic chemistry taking place on Titan and starting in its upper atmosphere is reminiscent of the groundbreaking Miller-Urey's historic experiment (Miller 1955; 1953; 1959) that demonstrated the necessity of a reducing atmosphere for the gas-phase organic synthesis to occur. Therefore, astrobiological studies on Titan (Raulin et al. 2009) might lead to the important conclusion that the organic synthesis of macromolecules in its atmosphere may ultimately bear a relationship with the prebiotic chemistry in the atmosphere of primitive earth despite the absence of reservoirs of liquid water on its surface. The search of carbocations, carbanions and of the corresponding neutrals as well as their role in gas-phase prebiotic chemistry might provide hints on the question of origin of life.

The first question to be answered is the following: Is astrochemistry the initiator of astrobiology (Smith, Cockell, and Leach 2013)? There are primarily two schools of thought. One school considers that the chemistry occurred in planet-forming interstellar clouds and then the prebiotic compounds were delivered to the early earth by comets or meteorites (Adande et al. 2013). The other school proposes that life originated on primitive earth by endogenous chemistry rather than exogenous processes, and the organic synthesis occurred in its atmosphere (Raulin et al. 2009, Horst et al. 2012). To support the second school of thought, astronomical searches for molecular species (with either infrared or millimeter astronomy) should be sought in extrasolar planets reminiscent of young earth and in the nitrogen-methane dominated Titan's thermosphere and ionosphere in order to place a link between organic atmospheric chemistry on Titan and the chemistry in the atmosphere of young earth at its earliest stage of formation in our solar system (Puzzarini et al. 2014b, 2014c). Detection of prebiotic species would thus confirm that the organic chemistry on Titan is a model of the prebiotic atmosphere of early earth.

Biopolymers, such as proteins, and RNA and DNA nucleic acids, are built from simple structures, such as amino acids (e.g., glycine) and nucleic acid bases (adenine, thymine, uracil, guanine, and cytosine). These should be therefore viewed as building blocks of complex biomolecules (Puzzarini and Barone 
2011, Barone et al. 2013, Puzzarini et al. 2014a). While biopolymers could be synthesized in the aqueous media, likely to be initiated by organic catalysis "on water", the open question is to which extent the elementary reactions in gas-phase chemistry could influence the production of the basic building blocks in space. The measurements by instruments onboard the Cassini spacecraft clearly demonstrated that simple molecules in the gas phase do evolve into organic macromolecules characterized by the structural complexity typical of pre-biological molecules. This has been pointed out in the present paper and can be summarized as follows. In Section 3, Tables 1.0 and 3.0 list the composition of a selection of complex molecules identified in the INMS ion measurements, such as hydrocarbons, nitriles, and nitrogen containing heterocycles. In Tables 2.0 and 4.0, we presented our analysis of the composition in the CAPS positive ion spectrum. The present analysis shows a chemical route to the formation of complex fused polycyclic hydrocarbons (such as $\mathrm{CH}_{2}{ }^{+}$substituted naphthalene $\mathrm{C}_{11} \mathrm{H}_{9}{ }^{+}$and the perinaphthenyl cation $\mathrm{C}_{13} \mathrm{H}_{9}{ }^{+}$) and $\mathrm{N}$-containing heterocycles (where a $\mathrm{CH}$ group of the polycyclic hydrocarbons is replaced by an $\mathrm{N}$ atom, like $\mathrm{C}_{12} \mathrm{H}_{8} \mathrm{~N}^{+}$) in Titan's upper atmosphere. Concerning the $\mathrm{C} \equiv \mathrm{N}^{+}$- bond present in many complex protonated nitriles, the current analysis also suggests the possible presence of imino groups $(>\mathrm{C}=\mathrm{N}-$ ) in stable carbonium ions giving rise to two isomers. The observation of negative ion chemistry in Titan's upper atmosphere by CAPS-ELS suggests an apparent antipodal relation between carbanions and carbocations. The electron recombination kinetics of cold closed-shell polyatomic ions with thermal electrons at low temperatures $(10-200 \mathrm{~K})$ then produces open-shell radicals. These radicals subsequently undergo radiative thermal electron attachment to form the corresponding complex molecular anions, such as $\mathrm{C}_{13} \mathrm{H}_{9}$. There are not yet any laboratory measurements of thermal electron-ion recombination rate coefficients for closed-shell polyatomic ions in the temperature range between 10 and $200 \mathrm{~K}$. Nevertheless, measurements of these recombination rate coefficients at room temperature for various radical PAH cations, such as the azulene $\left(\mathrm{C}_{10} \mathrm{H}_{8}\right)$ and acenaphthene $\left(\mathrm{C}_{12} \mathrm{H}_{10}\right)$ cations, have been carried out by means of the Flowing Afterglow with Photolons technique (Biennier et al. 2006). The measurements showed that the recombination of radical PAH cations is fast, and the rate coefficient increases with the number of carbon atoms of the PAH. Our analysis (presented in Section 3) of the observations of carbocations and carbanions from the Cassini instruments clearly shows the presence of diverse organic macromolecules of pre-biological importance in Titan's upper atmosphere. The chemical composition of Titan's haze is very poorly understood in the literature (Lavvas et al. 2013). The mechanism of formation and growth of macromolecules and their composition presented in this paper demonstrate that these macromolecular structures can further grow in Titan's upper atmosphere by means of carbocations chemistry. Future laboratory studies of the rates of mutual neutralization of the positive and negative ions by electron transfer mechanisms are also needed (Hickman 1978). The overall conclusion is that Cassini measurements demonstrated that the organic chemistry in Titan's upper atmosphere is quite active and complex.

The subsequent important question to address is whether photochemical production of complex molecules containing C, N, O, and $\mathrm{H}$ is possible in Titan's upper atmosphere (Puzzarini et al. 2014b, 2014c). The oxygen chemistry cannot be constrained by the instruments onboard the Cassini spacecraft (Puzzarini et al. 2014c). The introduction of $\mathrm{O}^{+}$from magnetosphere into the Titan's upper atmosphere was not known until its definitive detection by the CAPS measurements (Hartle et al. 2006) by lon Mass Spectrometer (IMS). Recent photochemical models suggest that these oxygen ions are incorporated into 
$\mathrm{CO}$ and $\mathrm{CO}_{2}$ (Horst et al., 2008). Although the presence of $\mathrm{CO}$ cannot be determined by the INMS data set, the $(\mathrm{C}, \mathrm{N}, \mathrm{O}, \mathrm{H})$ chemistry in the upper atmosphere of Titan may evolve from $\mathrm{N}_{2}, \mathrm{CH}_{4}$, and trace quantity of $\mathrm{CO}$ in presence of ultraviolet radiation and energetic electron impact (see Puzzarini et al. 2014c and references therein). Though the physicochemical conditions, such as temperature, pressure and UV radiation flux, cannot be reproduced in the laboratory simulation experiments, the work by Horst et al. (2012) demonstrates that molecules structurally similar and containing the same functional groups as in terrestrial prebiotic compounds could be formed in Titan's atmosphere at the high altitudes. In particular, protonated oxides of alkenes in Titan's upper atmosphere are of major interest, as they may initiate a completely new chemical pathway for complex prebiotic chemistry. Protonated oxirane in Titan's atmosphere has recently been considered as a case study (Puzzarini et al. 2014c). The nucleophilic ring rupture in the reaction of protonated oxirane with methylpropene is considered to be a model for the biosynthesis of the tetracyclic steroid precursor lanosterol in enzyme catalysed cyclization rearrangement reaction step of 2,3-oxidosqualene (Coxon and Townsend 2007; Corey et al. 1997). The computational study of the potential energy surface of ring-opening reaction of protonated oxirane with methylpropene suggests that the reaction is strongly exothermic with a low barrier, and the hyperconjugative stabilization of the carbocation plays a dominant role in the geometry of the intermolecular reaction product (Coxon and Townsend 2007). Future studies of cleavage reactions of protonated oxides of alkenes are therefore of great relevance in CHNO prebiotic chemistry (Puzzarini et al. 2014c).

On geologic timescales, the condensed-phase atmospheric macromolecular material once precipitated on Titan's surface evolves through the solute-solvent interaction chemistry. Concerning the molecular biology, the absence of permanent liquid water on the surface may be problematic for the emergence of biopolymers. The possible presence of a sub-surface ammonia-water ocean, and how meteoritic impacts and cryovolcanism at sites affect the composition by exposure to liquid water and processing for thousands of years are other open questions (Tobie et al. 2005, 2006,2009; Choukroun et al. 2007, 2008; Raulin 2008a). There is no observational evidence that Titan has a sub-surface ocean yet, even if Titan is the only planetary object other than earth that is known to have liquid solvents on its surface lakes (see Raulin 2008b and references therein). Based on an assumption of a thermodynamic equilibrium between the atmosphere and the lakes, which are considered non-ideal solutions, an estimate of the chemical composition can be derived, which shows (Cordier et al., 2009) that Titan's lakes are probably a mixture of liquid ethane $\left(\mathrm{C}_{2} \mathrm{H}_{6}\right)$, propane $\left(\mathrm{C}_{3} \mathrm{H}_{8}\right)$, and methane $\left(\mathrm{CH}_{4}\right)$ together with some minor components, like hydrogen cyanide $(\mathrm{HCN})$, butene $\left(\mathrm{C}_{4} \mathrm{H}_{8}\right)$, butane $\left(\mathrm{C}_{4} \mathrm{H}_{10}\right)$ and acetylene $\left(\mathrm{C}_{2} \mathrm{H}_{2}\right)$. Therefore, it is expected to have in Titan's lakes cold nonpolar solvents, whereas the solutes are generally polar organic macromolecules. Therefore, the thermodynamics of solubility and solvation appears to determine the rates of organic catalysis on lakes over geologic timescales. Unfortunately, there is no current mission to constrain the composition of organic lakes on Titan; very little is known, and we also do not know whether the dielectric stabilization of stable carbonium ion intermediates is the actual rate determining step in organic synthesis in Titan's liquid solvents (Surya Prakash and Schleyer 1997; Vogel 1985). By combining structural information for a water surface and electronic structure calculations with transition state theory, in a pioneering paper on the theory of organic catalysis "on water", Jung and Marcus (2007) suggested a molecular origin of the striking rate increase 
observed in a reaction on water with respect to homogeneous solution. The reaction in homogeneous aqueous solution is intrinsically slower than the surface reaction, as observed experimentally (see Jung and Marcus 2007, and references therein). The key argument for fast reaction kinetics on water is the structure of water molecules around a small hydrophobic solute in homogeneous solution versus the structural arrangement at the "oil-water" interface. The former does not permit a catalytic effect because it needs a breaking of an existing hydrogen-bond network in homogeneous solution. The assumption that aqueous organic reactions should always be performed in a homogeneous solution has been revised by Narayan et al. (2005), and rate accelerations can be achieved in the emulsion surfaces where reactants float. Therefore, because of the active organic chemistry in its most dense atmosphere and the presence of liquid phases on its surface, Titan appears to be a natural astrobiological laboratory in our solar system. In the case that the astrobiological question also relates to terrestrial prebiotic chemistry and the origin of life on earth, then Titan is the only planetary object in the solar system that will certainly provide a clue and a chemical answer. To explore astrobiology on Titan, a new mission is required, since the INMS and the CAPS instruments onboard the Cassini spacecraft are highly limited by their mass resolving capabilities (Waite et al. 2004; Young et al. 2004). One of the scientific payload instruments in such a mission must include a very high resolution mass spectrometer (Wiley and McLaren 1955; Mamyrin et al. 1973; Bergmann et al. 1989, 1990a, 1990b; Zajfman et al. 2003, 2004, Scherer et al. 2006; Balsiger et al. 2006) capable of measuring composition of cations, anions, and neutral constituents in the atmosphere in the mass range up to 10,000 amu approximately with a mass resolving capability of $\mathrm{M} / \Delta \mathrm{M} \sim 10^{5}$. Such compositional measurements are essential to understand organic synthesis of macromolecules in the atmosphere of Titan at various altitudes and to explore prebiotic atmospheric chemistry. The scientific payload must also include an instrument to carry out measurements of organic constituents in liquid bodies on Titan's surface using techniques such as the Electrospray lonization (ESI; Fenn et al. 1989; Whitehouse et al, 1985) time-of-flight mass spectrometry (Zajfman et al. 2003,2004). It is in fact well known the ESI technique allows for measurements of large biological molecules, keeping them intact without fragmentation in the ionization process. In addition to the measurements by the Atacama Large Millimeter/submillimeter Array (ALMA) and the James Webb Space Telescope (JWST) observations in the infrared (Gardner et al. 2006), planetary in situ measurements at millimeter and submillimeter wavelengths (Lellouch et al. 2010) should be carried out to provide molecular structures corresponding to the composition of carbocations, carbanions and neutrals detected by the Cassini instruments. Such spectroscopic measurements are the most critical to elucidate structural organic chemistry, and they are important to explain the mechanisms of organic synthesis in space. 


\section{Concluding Remarks and Future Studies}

The discovery of carbocations by the Ion Neutral Mass Spectrometer (INMS) and by the Cassini Plasma Spectrometer (CAPS) - Ion Beam Spectrometer (IBS), and of carbanions by the CAPS-Electron Spectrometer (ELS) has made a profound impact on the chemistry on planets. In a recently published paper (Ali et al. 2013), we provided a mechanistic interpretation of INMS observation of the numerous carbocations in Titan's upper atmosphere. This interpretation is based on the identification of carboncarbon bond formation dynamics in carbocationic chemistry (Olah 1972, 1995). The reactions of closedshell cations such as $\mathrm{CH}_{3}{ }^{+}$with polar and nonpolar molecules offer interesting examples of carbocationic chemistry. The reader is referred to Fig.1 in Ali et al. 2013, where the characteristics of potential energy surface for the reaction of $\mathrm{CH}_{3}{ }^{+}$with acetylene are given. Thus, an analysis of the Cassini INMS measurements (Ali et al. 2013) based on the chemistry of carbocations clearly revealed the mechanism of formation of three-membered Huckel aromatic rings (the cyclopropenyl cation and its cyclic methyl derivatives) in Titan's atmosphere at high altitudes. We also pointed that an understanding of the molecular structures and reactivity of carbocations (detected by instruments onboard the Cassini spacecraft) and their relevance to "nonclassical" carbo-ions can explain the aromaticity in the atmosphere of Titan and the chemical pathways toward prebiological molecules (Ali et al. 2013). On the basis of this carbocationic chemistry, in this paper we have identified the composition, the molecular structures and the chemistry at the basis of the growth of the complex macromolecules observed by the CAPS Ion Beam Spectrometer (IBS) and Electron Spectrometer (ELS).

The detected $\mathrm{CH}_{5}^{+}$(Waite et al., 2007) in Titan's upper atmosphere is the simplest Olah's carbocations, characterized by an unusual two-electron three-center $(2 \mathrm{e}, 3 \mathrm{c}$ ) bond structure (where sigma bonds are delocalized; Ali et al., 2013), and it has been identified as the origin of the complex carbocation chemistry. In Scheme 2.0 the most stable isomeric structures of the carbocations detected (Waite et al. 2007; Vuitton et al. 2009a) in Titan's thermosphere and ionosphere are depicted. In our earlier paper (Ali et al. 2013) we identified an important class of ion-molecule reactions proceeding via carbocation collision complexes, and we showed that the system evolves from this unusual pentacoordinated threecenter "nonclassical" methonium ion, $\mathrm{CH}_{5}{ }^{+}$, to complex organic structures (Scheme 2.0). In the present work, we furthermore demonstrated how the transition from the simplest Huckel's aromatic structures (cyclopropenyl cation and its cyclic methyl derivatives) to complex ortho-bridged bi- and tri-cyclic sixmembered ring hydrocarbons (e.g., $\mathrm{CH}_{2}{ }^{+}$mono-substituted napthalene and phenanthrene) as well as ortho- and peri-bridged tri-cyclic aromatic rings (e.g., perinaphthenyl cation) proceeds. These rings could further grow into larger ring polymers in the atmosphere of Titan at high altitudes: we refer the reader to Scheme 4.0 (Section 3.0) that provides the detailed analysis of the mechanisms of formation of the organic composition and molecular structure of the heavy compounds observed by the Cassini CAPS-IBS.

Contrary to the pre-Cassini observations, the nitrogen chemistry in Titan's upper atmosphere has been found to be extremely rich. Both the INMS observations (Table 3.0) and the CAPS-IBS measurements (Table 4.0) show the presence of a variety of $\mathrm{N}$-bearing carbocations in Titan's upper atmosphere, also including $\mathrm{N}$-heterocycles. We refer the reader to Scheme 6.0 that depicts the reaction pathways of the progression for chain reactions of ethylene with $\mathrm{C}_{6} \mathrm{H}_{5} \mathrm{NH}^{+}$. This scheme allows us to elucidate the formation mechanism of $\mathrm{N}$-heterocycles, such as $\mathrm{CH}_{2}{ }^{+}$mono-substituted derivative of benzopyridine 
$\mathrm{C}_{10} \mathrm{H}_{8} \mathrm{~N}^{+}$and the perinaphthenyl cation where a $\mathrm{CH}$ group is replaced by an $\mathrm{N}$ atom, $\mathrm{C}_{12} \mathrm{H}_{8} \mathrm{~N}^{+}$. The structure-reactivity analysis as well as the composition and molecular structure of a variety of nitrogencontaining carbocations observed by IBS are presented in Section 3.0.

One of the most important findings in astrochemistry is the recent discovery of molecular anions in space (Herbst and Millar 2008; Waite et al. 2007; Coates et al. 2007). Unlike the radio observations in interstellar space, the molecular anions in Titan's upper atmosphere were detected by CAPS-ELS (Waite et al. 2007; Coates et al. 2007). Our interest is in the intermediate region of the mass spectrum of the negative ions inferred from the energy/charge measurements by CAPS-ELS, i.e., between low mass molecular anions and the very large mass, negatively charged nano dimension particles. This intermediate region certainly carries information on the anions of very large organic molecules, the socalled carbanions. The chemistry of carbanions in Titan's upper atmosphere has not been developed yet. The observation of very large molecular anions by CAPS-ELS does not necessarily mean that the growth occurs by negative ion chemistry in Titan's upper atmosphere. Indeed, we propose that many closedshell complex carbocations undergo the kinetics of electron recombination to form open-shell neutral radicals, after a long series of chemical processes involving the formation of carbocations (Scheme 4.0 and Scheme 6.0). These neutral radicals with odd number of electrons subsequently form the carbanions via radiative electron attachment with thermal electrons at low electron temperatures $\left(T_{e}\right.$ $150 \mathrm{~K}$; Section 4.0). An illustrative example is provided by the perinaphthenyl anion $\mathrm{C}_{13} \mathrm{H}_{9}{ }^{-}$in Titan's upper atmosphere. The astronomical searches of the rotational transitions with millimeter astronomy of a few selected carbocations and their corresponding carbanions will most likely settle the key issue of the molecular anion chemistry on Titan. For this reason, in the second part of this paper we present accurate predictions for the rotational parameters that in turn can guide the search.

Furthermore, the chemistry in Titan's upper atmosphere may tell us a lot about the "abiotic" model of the synthesis of organics in interstellar clouds (Klemperer 2011), although the details of the ionmolecule reactions in the interstellar medium may differ in a subtle manner (Larsson et al. 2012; Herbst, and Millar 2008). It has also been largely acknowledged that Titan could represent a model of primitive earth. The chemistry of carbocations and carbanions in the nitrogen-methane dominated reducing environment of Titan at low temperatures and pressures is therefore immensely important. The radio and infrared searches of the selected molecules in the atmospheres of extrasolar planets reminiscent of young earth, as well as in Titan's atmosphere should be sought in order to place a clear linkage between the organic atmospheric chemistry on Titan and the prebiotic chemistry in the atmosphere of young earth at its earliest stage of formation in our solar system. Future earth-based telescopic studies using the interferometric observations with the Atacama Large Millimeter/submillimeter Array (ALMA) and/or in the infrared with the James Webb Space Telescope (JWST) will facilitate such searches of complex organic molecules. But, these require an accurate spectroscopic characterization of key ionic species. Work along this direction is thus of mandatory importance.

The observations from Cassini-Huygens thus pointed out that the organic chemistry on Titan is quite complex. No other planets or their satellites in our solar system have been found to bear similar levels of chemical complexity. This complexity indeed starts in the upper atmosphere at the very high altitude ( $900-1300 \mathrm{~km}$ ). The most notable examples of molecules in Titan's prebiotic atmospheric chemistry are 
the conjugated and aromatic polycyclic molecules, the $\mathrm{N}$-heterocycles including the presence of imino $>\mathrm{C}=\mathrm{N}-\mathrm{H}$ functional group, and a host of nitrogen-bearing hydrocarbons (see Table 3.0, Table 4.0, Scheme 3.0, and Scheme 6.0). Furthermore, besides earth, Titan is so far the only planetary object in our solar system that is known to possess permanent reservoirs of liquids on its surface (Raulin 2008a, 2008b). Although very little is known on the composition of these liquid mixtures on Titan, it certainly makes the synthesis of complex biomolecules possible either by catalysis of deposited organic solutes "on hydrocarbon" solvent or through the solvation process by unique reactivity of precipitated solutes. Despite the absence of permanent liquid water on Titan's surface, the observations of complex prebiotic molecules in the atmosphere at high altitude by all three instruments onboard the Cassini Spacecraft clearly indicate that Titan might provide a chemical perspective and an answer to the question of the organic compound synthesis on the primitive earth and the origin of life.

-This paper discusses the possible routes of organic synthesis in the atmosphere on Titan- a natural prebiotic laboratory. The chemistry of carbocations bears a direct evidence (Ali et al. 2013) of a molecular growth at high altitudes of Titan's atmosphere based on measurements by the instruments onboard the Cassini spacecraft. The argument presented throughout this paper is mechanistic : we have provided the molecular structure of carbonium ions that are at the basis of the chemical synthesis of significant organic compounds (e.g. aromatic polycyclic molecules, N-heterocycles) in our solar system. Our synthetic routes and mechanisms support the view that Titan is a model of prebiotic earth and the beginning of biological synthesis. It has been demonstrated that the organic synthesis on Titan produces molecules that have a similar structural complexity as in terrestrial prebiotic molecules. It thus tantalizes that similar carbocationic processes could have existed in the reducing atmosphere of primitive earth and played a fundamental role in the formation of the significant organic molecules related to prebiotic life (e.g. the pyrimidine and purine derivatives nucleobases, the ribose- a cyclic five-membered ring structure sugar). To understand the organic synthesis on Titan and to further elucidate structural organic chemistry, we reiterate for the need of spectroscopic detection (Puzzarini et al. 2011, 2013, 2014a, 2014b, 2014c) of significant organic cationic and anionic molecules by means of broad infrared astronomical observations using the James Webb Space Telescope (JWST) and the high resolution EXES instrument mounted on Stratospheric Observatory for Infrared Astronomy (SOFIA) in the mid infrared region. In addition to the detection of these molecules in space by rotation-vibration spectroscopy, their pure rotational spectra (Puzzarini et al. 2010, 2013, 2014c; Ali et al. 2013) could also be probed spatially with interferometric ALMA in the millimeter/submillimeter wavelength region. What Cassini allowed us to point out is that Titan is characterized by the same molecules and carbonium chemistry as the prebiotic Earth - but on a different planetary body in our solar system.

\section{Acknowledgments}

This work was supported in part at NASA Goddard Space Flight Center by the Cassini Plasma Spectrometer (CAPS) Project through NASA Jet Propulsion Laboratory contract 1243218 with Southwest Research Institute in San Antonio, Texas. C.P. acknowledges support by Italian MIUR (PRIN 2012: Project "STAR: Spectroscopic and computational Techniques for Astrophysical and atmospheric Research") and by the University of Bologna (RFO funds). We are grateful to both anonymous referees for a careful 
reading of the manuscript and of the different perspectives provided. The interested readers may treat the highlighted portion in a bulleted format in the last section of this manuscript as a footnote. 


\section{References}

Adande, G.R., Woolf, N.J., Ziurys, L.M., 2013. Observations of Interstellar Formamide: Availability of a Prebiotic Precursor in the Galactic Habitable Zone. Astrobiology. 13, 439-453.

Agundez, M., Cernicharo, J., et al., 2010. Astronomical identification of CN- , the smallest observed molecular anion. Astronomy.Astropphys. 517,L2.

Ali, A., Sittler Jr., E.C., Chornay, D., Rowe, B.R., Puzzarini, C., 2013. Cyclopropenyl cation - the simplest Huckel's aromatic molecule - and its cyclic methyl derivatives in Titan's upper atmosphere. Planet.

Space Sci. 87, 96 -105.

Ali, A., Chornay,D., Sittler Jr., E.C., Canosa, A., 2010. Gas-Phase Prebiotic Chemistry on Titan: Specific Laboratory Kinetic Measurements on the Formation Rates and Mechanisms for Molecular Anions Observed by the Cassini Mission: In: Proceedings of the Titan Through Time: a Workshop on Titan's Formation, Evolution and Fate. NASA, Goddard Space Flight Center, p.79.

Balsiger, H., Altwegg, K., et al., 2006. Rosetta Orbiter Spectrometer for lon and Neutral Analysis ROSINA. ESA SP-1165.

Balucani, N., 2009. Elementary Reactions and Their Role in Gas-Phase Prebiotic Chemistry. Int. J. Mol. Sci. 10, 2304-2335.

Barone, V., Biczysko, M., Bloino, J., Puzzarini, C., 2013. Accurate structure, thermodynamic and Spectroscopic parameters from CC and CC/DFT schemes: the challenge of the conformational equilibrium in glycine. Phys. Chem. Chem. Phys. 15, 10094-10111.

Basu, R., Bose, S.K., 1966. Simple Huckel Calculation on Triphenyl Cyclopropenyl Cation. Theoret. Chim. Acta. 4, 94-97.

Bates, D.R., Herbst, E., 1988. Radiative Association.In: Millar, T.J., Williams, D.A. (Eds.). Rate Coefficients in Astrochemistry. Kluwer Academic Publishers. pp. 17-40.

Bauschlicher Jr., C.W., Bakes, E.L.O., 2000. Infrared spectra of polycyclic aromatic hydrocarbons (PAHs). Chem.Phys. 262, 285-291.

Bergmann, T., Martin, T.P., Schaber, H., 1989. High-resolution time-of-flight mass spectrometers: Part I. Effects of field distortions in the vicinity of wire meshes. Rev.Sci.Instrum. 60, 347-349.

Bergmann, T., Martin, T.P., Schaber, H., 1990. High-resolution time-of-flight mass spectrometers. Part II. Cross beam ion optics. Rev.Sci.Instrum. 61, 2585-2591.

Bergmann, T., Martin, T.P., Schaber, H., 1990. High-resolution time-of-flight mass spectrometers. Part III. Reflector design. Rev.Sci.Instrum. 61, 2592-2600.

Biennier, L., Alsayed-Ali, M., et al., 2006. Laboratory measurements of the recombination of PAH ions with electrons: implications for the PAH charge state in interstellar clouds. Faraday Discuss. 133, 289-301.

Brownsword, R.A., Sims, I.R., Smith, I.W.M., Stewart, D.W.A., Canosa, A., Rowe, B.R., 1997. The Radiative Association of $\mathrm{CH}$ with $\mathrm{H}_{2}$ : A Mechanism for Formation of $\mathrm{CH}_{3}$ in Interstellar Clouds. Astrophys.J. 485, 195-202.

Brunken, S., Gupta, H., Gottlieb, C.A., McCarthy, M.C., Thaddeus, P., 2007. Detection of the Carbon Chain Negative lon $\mathrm{C}_{8} \mathrm{H}^{-}$in TMC-1. Astrophys.J. 664, L43-L46.

Carles, S., Adjali, F., Monnerie,C., Guillemin,J.-C., LeGarrec,J.-L., 2011. Kinetic studies at room temperature of the cyanide anion $\mathrm{CN}^{-}$with cyanoacetylene $\left(\mathrm{HC}_{3} \mathrm{~N}\right)$ reaction. Icarus. 901-905. 
Cazzoli, G., Puzzarini, C., 2006. Observation of OD` Using Microwave Spectroscopy: A new Candidate for Astrophysical Detection. Astrophys.J. 648, L79-L81.

Cernicharo,J., Guelin,M., Agundez,M., et al., 2007. Astronomical detection of $\mathrm{C}_{4} \mathrm{H}^{-}$, the second interstellar anion. Astron.Astrophys. 467, L37-L40.

Choukroun,M., Grasset,O., 2007. Thermodynamic model for water and high-pressure ices up to $2.2 \mathrm{GPa}$ and down to the metastable domain. J.Chem.Phys. 127, 124506-124511.

Choukroun,M., Grasset,O., Sotin,C., Tobie,G., 2008. Cryovolcanic Release of Methane on Titan: Experimental Constraints from the Stability of Methane Clathrates in Presence of Ammonia. Lunar Planet.Sci.Conf. XXXIX. abstract\#1837. Houston,TX.

Clary, D.C., 1988a. Theory of reactive collisions at low temperatures. In: Millar, T.J., Williams,D.A. (Eds). Rate Coefficients in Astrochemistry. Kluwer Academic Publishers. pp. 1-16.

Clary, D.C., 1988b. Photodetachment of electrons from Dipolar Anions. J.Phys.Chem. 92, 3173-3181.

Clary, D.C., 1990. Fast Chemical Reactions: Theory Challenges Experiment. Annu.Rev.Phys.Chem. 41, 61-90.

Coates A.J., Crary, F.J., Lewis, G.R., Young, D.T., Waite Jr., J.H., Sittler Jr., E.C., 2007. Discovery of heavy negative ions in Titan's ionosphere. Geophys.Res.Lett. 34, L22103.

Coates, A.J., Wellbrock,A., Lewis, G.R., Jones, G.H., Young, D.T., Crary, F.J., Waite Jr., J.H., 2009. Heavy negative ions in Titan's ionosphere: Altitude and latitude dependence. Planet. Space Sci. 57,1866-1871

Coates, A.J., Wellbrock,A., Lewis,G.R., Jones,G.R., Young,D.T., Crary,F.J., Waite Jr., J.H., Johnson,R.E., Hill, T.W., Sittler Jr.,E.C., 2010. Negative Ions at Titan and Enceladus: Recent Results. Faraday Discussions. 147, 293-305.

Cordier, D., Mousis, O., Lunine, J.I., Lavvas, P., Vuitton, V., 2009. An estimate of the chemical composition of Titan's Lakes. Astrophys.J. 707, L128-L131.

Corey, E.J., Cheng, H., Baker, C.H., et al., 1997. Methodology for the Preparation of Pure Recombinant S.cerevisiae Lanosterol Synthase Using a Baculovirus Expression System. Evidence That Oxirane Cleavage and A-Ring Formation Are Concerted in the Biosynthesis of Lanosterol from 2,30xidosqualene. J.Amer.Chem.Soc. 119,1277-1288.

Coxon, J.M., Townsend, A.E., 2007. Computational study on the ring-opening reaction of protonated oxirane and methylpropene. Tetrahedron. 63, 5665-5668.

Cram, D.J., 1965. Fundamentals of Carbanion Chemistry. Academic Press. New York-London.

Crary, F.J., Magee, B.A., Mandt, K., Waite Jr., J.H., Westlake, J., Young, D.T., 2009. Heavy ions, temperatures and winds in Titan's ionosphere: Combined Cassini CAPS and INMS observations. Planet. Space Sci. 57, 1847-1856.

Crocker, L., Wang, T., Kebarale, P., 1993. Electron affinities of some polycyclic aromatic hydrocarbons, obtained from electron-transfer equilibria. J.Am.Chem.Soc. 115, 7818-7822.

Dupeyrat, G., Marquette, J.B., Rowe, B.R., 1985. Design and testing of axisymmetric nozzles for ionmolecule reaction studies between $20^{\circ} \mathrm{K}$ and $160^{\circ} \mathrm{K}$. Phys.Fluids. 28, 1273-1279.

Ervin, K.M., Gronert, S., et al., 1990. Bond Strengths of Ethylene and Acetylene. J.Am.Chem.Soc. 112, 5750-5759.

Fenn, J.B., Mann, M., Meng, C.K., Wong, S.F., Whitehouse, C.M., 1989. Electrospray lonization for Mass Spectrometry of Large Biomolecules. Science. 246, 64-71.

Gardner, J.P., Mather, J.C., et al., 2006. The James Webb Space Telescope. Space Science Reviews. 123, 
485-606.

Gerin, M., 2013. The Molecular Universe. In: Smith,I.W.M. et el. (Eds). Astrochemistry and Astrobiology, Physical Chemistry in Action. Springer-Verlag Berlin Heidelberg. pp. 35-72.

Gerlich, D., Horning, S., 1992. Experimental investigations of radiative association processes as related to interstellar chemistry. Chem.Rev. 92,1509-1539.

Gilbert, R.G., Smith, S.C., 1990. Theory of Unimolecular and Recombination Reactions. Blackwell Scientific. Boston.

Gotkis, I., Lifshitz, C., 1993. Time-dependent Mass Spectra and Breakdown Graphs. 16- The Methylnaphthalenes. Org. Mass. Spectrom. 28, 372-377.

Gottlieb, C.A., Brunken, S., McCarthy, M.C., Thaddeus, P., 2007. The rotational spectrum of CN'. J.Chem.Phys. 126, 191101-1 - 191101-4.

Gygax, R., Lee McPeters, H., Brauman, J.I., 1979. Photodetachment of Electrons from Anions of High Symmetry. Electron Photodetachment Spectra of the Cyclooctatetraenyl and Perinaphthenyl Anions. J.Am.Chem.Soc. 101:10, 2567-2570.

Gupta, H., Brunken,S., Tamassia,F., et al., 2007. Rotational Spectra of the Carbon Chain Negative lons $\mathrm{C}_{4} \mathrm{H}^{-}$and $\mathrm{C}_{8} \mathrm{H}^{-}$. Astrophys.J. 655, L57-L60.

Guthe, F., Tulej, M., Pachkov, M.V., Maier, J.P., 2001. Photodetachment Spectrum of $\mathrm{I}-\mathrm{C}_{3} \mathrm{H}_{2}{ }^{-}$: The Role of Dipole Bound States for Electron Attachment in Interstellar Clouds. Astrophys.J. 555, 466-471.

Hariharan,P.C., Radom,L., Pople,J.A., Schleyer,P.v.R., 1974. Molecular Orbital Theory of the Electronic Structure of Organic Compounds. XX. $\mathrm{C}_{3} \mathrm{H}_{7}{ }^{+}$Cations with a Polarized Basis Set. J.Amer.Chem.Soc. 96:2, 599-601.

Hartle,R.E., SittlerJ.,E.C., Neubauer,F.M. et al., 2006. Preliminary Interpretation of Titan Plasma Interaction as Observed by the Cassini Plasma Spectrometer: Comparisons with Voyager 1, Geophys.Res.Lett. 33, L08201.

Herbst,E., 1981. Can negative molecular ions be detected in dense interstellar clouds? Nature. 289, 656-657.

Herbst, E., 2001. The Chemistry of Interstellar Space. Chem.Soc.Rev. 30, 168-176.

Herbst, E., 2005. Chemistry of Star-Forming Regions. J.Phys.Chem. 109,4017-4029.

Herbst, E., Millar, T.J., 2008. The Chemistry of Cold Interstellar Cloud Cores. In: Smith,I.W.M. (Ed). Low Temperatures and Cold Molecules. Imperial College Press. pp.1-54.

Herbst, E., Osamura, Y., 2008. Calculations on the Formation Rates and Mechanisms for $\mathrm{C}_{n} \mathrm{H}$ Anions in Interstellar and Circumstellar Media. Astrophys.J. 679, 1670-1679.

Hickman, A.P., 1979. Approximate scaling formula for ion-ion mutual neutralization rates. J.Chem.Phys. 70, 4872-4878.

Hoffmann, R., 1964a. Extended Huckel theory. IV. Carbonium Ions. J.Chem.Phys. 40, 2480-2488.

Hoffmann,R., 1964b. Toward an Understanding of Nonclassical Carbonium Ions. J.Amer.Chem.Soc. 86, 1259-1261.

Holbrook, K.A., Pilling, M.J., Robertson, S.H., 1996. Unimolecular Reactions. Ed. 2. Wiley, New York. Horst,S.M., Vuitton,V., Yelle,R.V., 2008. Origin of oxygen species in Titan's atmosphere. J.Geophys.Res. 113, E10006, pp.1-14.

Horst, S.M., Yelle, R.V., et al., 2012. Formation of Amino Acids and Nucleotide Bases in a Titan Atmosphere Simulation Experiment. Astrobiology. 12,809-817. 
Huang, F-S., Dunbar, R.C., 1990. Time-Resolved Photodissociation of Methylnaphthalene Ion. An Illustration of Kinetic Shifts in Large-Ion Dissociations. J. Am. Chem. Soc. 112, 8167-8169.

Jan, Z., Romanzin, C., Alcaraz, C., Polasek, M., 2012. Anion chemistry on Titan: A possible route to large $\mathrm{N}$-bearing hydrocarbons. Icarus. 219, 161-167.

Jung, Y., Marcus, R.A., 2007. On the Theory of Organic Catalysis "on Water" J. Am. Chem. Soc. 129, 5492-5502.

Klemperer, W., 2011. Astronomical Chemistry. Annu. Rev. Phys. Chem. 62, 173-184.

Klippenstein, S.J., Georgievskii, Y., 2008. Theory of low temperature gas-phase reactions. In: Smith, I.W.M. (Ed). Low Temperatures and Cold Molecules. Imperial College Press. pp.175-229.

Larsson, M., Geppert, W.D., Nyman, G., 2012. Ion Chemistry in Space. Report. Prog. Phys. 75(066901). (75pp.).

Lavvas, P., Yelle, R.V., et al., 2013. Aerosol growth in Titan's ionosphere. PNAS. 110, 2729-2734.

Lellouch, E., Vinatier, S., et al., 2010. Sounding of Titan's atmosphere at submillimeter wavelengths from an orbiting spacecraft. Planet.Space Sci. 58, 1724-1739.

Linder, D.R., Coates, A.J., et al., 1998. The Cassini CAPS Electron Spectrometer. In: Pfaff,R.F., et al. (Eds.). Measurement Techniques in Space Plasmas: Particles. AGU Geophysical Monograph. pp.257-262.

Lopez, R., Sordo, J.A., Sordo, T.L., Schleyer, P.V.R., 1996. Ab initio study of the formation of $\mathrm{C}_{3} \mathrm{H}_{3}{ }^{+}$from the reaction of $\mathrm{CH}_{3}{ }^{+}$with acetylene. Journal of Computational Chemistry. 17, 905-909.

Lorenz, R.D., Lunine, J.I., Neish, C.D., 2011. Cyanide Soap? Dissolved material in Titan's Seas. EPSC Abstracts. Vol.6., EPSC-DPS2011-488.

Lykke, K.R., Neumark, D.M., Andersen, T., Trapa, V.J., Lineberger, W.C., 1987. Autodetachment spectroscopy and dynamics of $\mathrm{CH}_{2} \mathrm{CN}^{-}$and $\mathrm{CD}_{2} \mathrm{CN}^{-}$. J.Chem.Phys. 87, 6842-6853.

Mamyrin, B.A., Karataev, V.I., Shmikk, D.V., Zagulin., 1973. The Mass-reflectron, a new nonmagnetic time-of-flight mass spectrometer with high resolution. Sov.Phys.Jetp. 37, 45-48.

Marcus, R.A., 2009. Interaction between Experiments, Analytical Theories, and Computation. J.Phys.Chem. 113, 14598-14608.

McCarthy, M.C., Gottlieb, C.A., Gupta, H., Thaddeus, P., 2006. Laboratory and Astronomical Identification of the Negative Molecular lon $\mathrm{C}_{6} \mathrm{H}^{-}$. Astrophys.J. 652, L141-L144.

McCarthy, M.C., Thaddeus, P., 2008. High-resolution rotational spectroscopy of the carbon chain anions $\mathrm{C}_{3} \mathrm{~N}-, \mathrm{C}_{4} \mathrm{H}-$, and $\mathrm{C}_{4} \mathrm{D}-$. J.Chem.Phys. 129, 054314-1 - 054314-6.

Millar, T.J., Walsh, C., Cordiner, M.A., Chuimin, R.Ni, Herbst, E., 2007. Hydrocarbon Anions in Interstellar Clouds and Circumstellar Envelopes. Astrophys.J. 662, L87-L90.

Miller, S.L., 1953. A Production of Aminoacids Under Possible Primitive Earth Conditions. Science. 117, 528-429.

Miller, S.L., 1955. Production of Some Organic Compounds under Possible Primitive Earth Conditions. J.Am.Chem.Soc. 77, 2351-2361.

Miller, S.L., Urey, H.C., 1959. Organic Compound Synthesis on the Primitive Earth. Science. 130, 245-251. Moreno, R., Lellouch, E., et al., 2011. First detection of hydrogen isocyanide (HNC) in Titan's atmosphere Astron.Astrophys. 536, L12.

Moustefaoui, T., Rebrion-Rowe, C., Le Garrec, J-L., Rowe, B.R., Mitchell, J.B.A., 1998. Low temperature electron attachment to polycyclic aromatic hydrocarbons. Faraday Discuss.,109, 71-82.

Narayan, S., Muldoon, J., Finn, M.G., Fokin, V.V., Kolb, H.C., Sharpless, K.B., 2005. On Water: Unique 
Reactivity of Organic Compounds in Aqueous Suspension. Angew. Chem.Int.Ed. 44, 3275-3279. Niemann, H.B., Atreya, S.K., et al., 2005. The composition of Titan's atmosphere from the GCMS on the Huygens probe, and implications for the origin of nitrogen and methane. Nature. 438,779-784. Olah, G.A.,Kiovsky, T.E., 1968. Stable Carbonium Ions. LXV. Protonation of Hydrogen Cyanide and Alkylnitriles in $\mathrm{FSO}_{3} \mathrm{H}-\mathrm{SbF}_{5}-\mathrm{SO}_{2}$ Solution. Comparative Study of Meerwein's N-Alkylnitrilium lons. J.Am.Chem.Soc. 90, 4666-4672.

Olah, G.A., Klopman, G., 1971. A Possible Tetracoordinated Three-Center Bound Configuration of the Methane Radical Cation, $\mathrm{CH}_{4}{ }^{+}$. Chem. Phys.Lett. 11, 604-608.

Olah, G.A., 1972. The General Concept and Structure of Carbocations Based on Differentiation of Trivalent ("Classical") Carbenium Ions from Three-Center Bound Penta- or Tetracoordinated ("Nonclassical") Carbonium Ions. The Role of Carbocations in Electrophilic Reactions. J.Am.Chem.Soc. 94, 808-820.

Olah, G.A., 1995. My Search for Carbocations and Their Role in Chemistry (Nobel lecture). Angew.Chem. Int. Ed. England. 34, 1393-1405.

Petrie, S., 1996. Novel pathways to $\mathrm{CN}^{-}$within interstellar clouds and circumstellar envelopes: implications for IS and CS chemistry. Mon.Not.Roy.Astron.Soc. 281, 137-144.

Petrie,S., 2001. Hydrogen Isocyanide, HNC: A Key Species in the Chemistry of Titan's lonosphere? Icarus. 151, 196-203.

Petrie, S., Chirnside, T.J., Freeman, C.G., McEwan, M.J., 1991. The Ion/Molecule Chemistry of $\mathrm{CH}_{2} \mathrm{CHCN}$. Int.J.Mass.Spectrom.Ion Process. 107, 319-331.

Petrie, S., Herbst, E., 1997.Some interstellar reactions involving electrons and neutral species: Attachment and isomerization. Astrophys.J. 491, 210-215.

Puzzarini, C., 2013. Rotational spectroscopy meets theory. Phys.Chem.Chem.Phys. 15, 6595-6607.

Puzzarini, C., Barone, V., 2011. Extending the molecular size in accurate quantum-chemical calculations: the equilibrium structure and spectroscopic properties of uracil. Phys.Chem.Chem.Phys. 13,7158-7166

Puzzarini, C., Biczysko, M., Barone, V., Largo, L., Pena, I., Cabezas, C., Alonso, J. L., 2014a. Accurate Characterization of the Peptide Linkage in the Gas Phase: A Joint Quantum-Chemical and Rotational Spectroscopy Study of the Glycine Dipeptide Analogue. J. Phys. Chem. Lett. 5, 534-540.

Puzzarini, C., Biczysko, M., Bloino, J., Barone, V., 2014b. Accurate spectroscopic characterization of oxirane: a valuable route to its identification in Titan's atmosphere and the assignment of unidentified Infrared bands. Astrophys.J. 785, 107.

Puzzarini, C., Ali, A., Biczysko, M., Barone, V., 2014c. Accurate spectroscopic characterization of protonated oxirane: a potential prebiotic species in Titan's atmosphere. Astrophys.J.

792:118 (6pp).

Puzzarini, C., Stanton, J.F., Gauss, J., 2010. Quantum-chemical calculation of spectroscopic parameters for rotational spectroscopy. Int.Reviews.Phys.Chem. 29, 273-367.

Raulin, F., 2008a. Astrobiology and Habitability of Titan. Space Sci Rev. 135, 37-48.

Raulin, F., 2008b. Organic lakes on Titan. Nature. 454, 587-589.

Raulin, F., McKay, C., Lunine, J., Owen, T., 2009. Titan's Astrobiology. In: Brown,R.H. et al. (Eds). Titan from Cassini-Huygens. Springer. pp. 215-233.

Remijan, A.J., Hollis, J.M., Lovas, F.J., Cordiner, M.A., Millar, T.J., 2007. Detection of $\mathrm{C}_{8} \mathrm{H}^{-}$and Comparison with $\mathrm{C}_{8} \mathrm{H}$ toward IRC +10216 . Astrophys.J. 664, L47-L50. 
Rienstra-Kiracofe, J.C., Barden, C.J., Brown, S.T., Schaefer III, H.F., 2001. Electron Affinities of Polycyclic Aromatic Hydrocarbons J.Phys.Chem.A. 105, 524-528.

Robinson, P.J., Holbrook, K.A., 1972. Unimolecular Reactions. Wiley-Interscience. New York.

Rowe, B.R., Canosa, A., Page, V.L., 1995. FALP and CRESU studies of ionic reactions. Int.J.Mass.Spectrom. Ion Processes. 149/150, 573-596.

Rowe, B.R., Dupeyrat, G., Marquette, J.B., Gaucherel, P., 1984. Study of the reactions $\mathrm{N}_{2}{ }^{+}+2 \mathrm{~N}_{2} \rightarrow \mathrm{N}_{4}{ }^{+}+\mathrm{N}_{2}$ and $\mathrm{O}_{2}{ }^{+}+2 \mathrm{O}_{2} \rightarrow \mathrm{O}_{4}{ }^{+}+\mathrm{O}_{2}$ from 20 to $160 \mathrm{~K}$ by the CRESU technique. J.Chem.Phys. 80, 4915-4921.

Sakai, N., Sakai, T., Osamura, Y., Yamamoto, S., 2007. Detection of $\mathrm{C}_{6} \mathrm{H}^{-}$toward the low-mass protostar IRAS $04368+2557$ in L1527. Astrophys.J. 667, L65-L68.

Sakai, N., Sakai, T., Yamamoto, S., 2008. Tentative detection of $\mathrm{C}_{4} \mathrm{H}^{-}$toward the low-mass protostar IRAS $04368+2557$ in L1527. Astrophys.J. 673, L71-L74.

Scherer, S., Altwegg, K., Balsiger, H., et al., 2006. A novel principle for an ion mirror design in time-offlight mass spectrometry. Int.J.Mass.Spectrom. 251, 73-81.

Schiedt, J., Weinkauf, R., 1997. Photodetachment photoelectron spectroscopy of perylene and $\mathrm{CS}_{2}$ : two extreme cases. Chem.Phys.Lett. 274, 18-22.

Schiedt, J., Weinkauf, R., 1997. Photodetachment photoelectron spectroscopy of mass selected anions: anthracene and the anthracene $-\mathrm{H}_{2} \mathrm{O}$ cluster. Chem.Phys.Lett. 266, 201-205.

Simons, J., Jordan, K.D., 1987. Ab Initio Electronic Structure of Anions. Chem.Rev. 87, 535-555.

Sittler Jr., E.C., Ali, A., Cooper, J.F., Hartle, R.E., Johnson, R.E., Coates, A.J., Young, D.T., 2009.

Heavy lon Formation in Titan's lonosphere: magnetospheric introduction of free oxygen and a source of Titan's aerosols? Planet. Space Sci. 57, 1547-1557.

Smith, I.W.M., 1989. Effects of Quantum Mechanical Tunneling onRates of Radiative Association.

Astrophys.J. 347, 282-288.

Smith, I.W.M., Rowe, B.R., 2000. Reaction Kinetics at Very Low Temperatures: Laboratory Studies and Interstellar Chemistry. Acc.Chem.Res. 33, 261-268.

Smith, I.W.M., 2002. Chemistry amongst the stars: reaction kinetics at a new frontier. Chem.Soc.Rev. 31,137-146.

Smith, I.W.M., 2006. Reactions at very low temperatures: Gas kinetics at a new frontier. Angew.Chem. Int. Ed.45, 2842-2861.

Smith, I.W.M., Cockell, C.S., Leach, S., 2013. Astrochemistry and Astrobiology, Physical Chemistry in Action Springer-Verlag, Berlin Heidelberg.

Sonnenfroh, D.M., Farrar, J.M., 1986. Collision complexes in the reactions of $\mathrm{CH}_{3}{ }^{+}$with $\mathrm{C}_{2} \mathrm{H}_{4}$ and $\mathrm{C}_{2} \mathrm{H} 2$. J.Chem.Phys. 85, 7167-7177.

Surya Prakash, G.K., Schleyer,P.v.R., 1997. Stable Carbocation Chemistry. John Wiley \& Sons.

Taylor, T.R., Xu, C., Neumark, D.M., 1998. Photoelectron spectra of the $\mathrm{C}_{2 n} \mathrm{H}^{-}(\mathrm{n}=1-4)$ and $\mathrm{C}_{2 \mathrm{n}} \mathrm{D}^{-}(\mathrm{n}=1-3)$ anions. J.Chem.Phys. 108, 10018-10026.

Thaddeus, P., Gottlieb, C.A., Gupta, H., et al., 2008. Laboratory and Astronomical Detection of the Negative Molecular Ion $\mathrm{C}_{3} \mathrm{~N}^{-}$. Astrophys. J. 677, 1132-1139.

Tobie,G., Grasset,O., Lunine,J., Mocquet,A., Sotin,C., 2005. Titan's internal structure inferred from a coupled thermal-orbital model. Icarus. 175, 496-502.

Tobie,G., Lunine,J., Sotin,C., 2006. Episodic outgassing as the origin of atmospheric methane on Titan. Nature. 440, 61-64. 
Tobie,G., Choukroun,M., Grasset,O., et al., 2009. Evolution of Titan and implications for its hydrocarbon cycle. Phil.Trans R.Soc A.367, 619-631.

Truhlar, D.G., Garrett, B.C., Klippenstein, S.J., 1996. Current Status of Transition-State Theory. J.Phys.Chem. 100, 12771-12800.

Vogel, P., 1985. Carbocation Chemistry. Elsevier. Oxford.

Vuitton, V., Yelle, R.V., Lavvas, P., Klippenstein, S.J., 2012. Rapid Association Reactions at Low Pressure: Impact on the Formation of Hydrocarbons on Titan. Astrophys.J. 744(11).(7pp).

Vuitton, V., Yelle, R.V., Lavvas, P., 2009a. Composition and chemistry of Titan's thermosphere and ionosphere. Phil.Trans.R.Soc. A. 367, 729-741.

Vuitton, V., Lavvas, P., Yelle, R.V., Galand, M., Wellbrock, A., Lewis, G.R., Coates, A.J., Wahlund, J.-E., 2009b. Negative ion chemistry in Titan's upper atmosphere. Planet. Space Sci. 57,1558-1572.

Waite Jr., J.H., Young, D.T., Coates, A.J., Crary, F.J., Magee, B.A., Mandt, K.E., Westlake, J.H., 2008. The source of heavy organics and aerosols in Titan's atmosphere. In: Kwok, S., Sandford, S., (Eds). Organic Matter in Space. Proceedings IAU Symposium No. 251. 321-326.

Waite Jr., J.H., Young, D.T., Westlake, J.H., Lunine, J.I., McKay, C.P., Lewis, W.S., 2009. High -altitude production of Titan's aerosols. In: Brown,R.H., et al. (Eds.). Titan from Cassini-Huygens. Springer. pp. 201-214.

Waite Jr., J.H., Niemann, H.B., et al., 2005. Ion neutral mass spectrometer results from the first flyby of Titan. Science. 308, 982-986.

Waite Jr., J.H., Lewis, W.S., et al., 2004. The Cassini ion and neutral mass spectrometer (INMS) investigation. Space. Science Reviews. 114, 113-231.

Waite Jr., J.H., Young, D.T., Cravens, T.E., Coates, A.J., Crary, F.J., Magee, B., Westlake, J., 2007, The Process of tholin formation in Titan's upper atmosphere. Science. 316, 870-875.

Wellbrock,A., Coates, A.J., Jones,G.H., Lewis,G.R., Waite, J.H., 2013. Cassini CAPS-ELS observations of negative ions in Titan's ionosphere: Trends of density with altitude. Geophys. Res. Lett. 40, 4481- 4485.

Wetzel, D.M., Brauman, J.I., 1987. Electron Photodetachment Spectroscopy of Trapped Negative lons. Chem.Rev. 87, 607-622.

Whitehouse, C.M., Dreyer, R.N., Yamashita, M., Fenn, J.B., 1985. Electrospray Interface for Liquid Chromatographs and Mass Spectrometers. Anal.Chem. 57, 675-679.

Wigner,E.P., 1948. On the Behavior of Cross Sections Near Thresholds. Phys.Rev. 73, 1002-1009.

Wiley, W.C., McLaren, I.H., 1955. Time-of-Flight Mass Spectrometer with Improved Resolution. Rev.Sci.Instrum. 26,1150-1157.

Wilson, E.H., Atreya, S.K., 2004. Current state of modeling the photochemistry of Titan's mutually dependent atmosphere and ionosphere. J.Geophys.Res. 109, E06002.

Wuest, M., 1998. Time-of-Flight Ion Composition Measurement Technique for Space Plasmas. In: Pfaff, R.F. et al. (Eds). Measurement Techniques in Space Plasmas. Am.Geophys.Union. pp.141-155.

Yokoyama, K., Leach, G.W., Kim, J.B.,Lineberger, W.C., 1996. Autodetachment spectroscopy and dynamics of dipole bound states of negative ions: ${ }^{2} \mathrm{~A}_{1}-{ }^{2} \mathrm{~B}_{1}$ transitions of $\mathrm{H}_{2} \mathrm{CCC}$. J.Chem. Phys. 105, 10696-10705

Yokoyama, K., Leach, G.W., Kim, J.B., Lineberger, W.C., Boldyrev, A.I., Gutowski, M., 1996.

Autodetachment spectroscopy and dynamics of vibrationally excited dipole-bound states of $\mathrm{H}_{2} \mathrm{CCC}^{-}$. J.Chem.Phys. 105, 10706-10718. 
Young, D.T., Barraclough,B.L., et al., 1998. Cassini plasma spectrometer investigation. In: Pfaff,R.F., et al. (Eds.), Measurement Techniques in Space Plasmas:Particles. AGU Geophys Monograph. pp.237-242. Young, D.T., Berthelier, J.J., et al., 2004. Cassini plasma spectrometer investigation. Space. Science Reviews. 114, 1-112.

Yung, Y.L., Allen, M., Pinto, J.P., 1984. Photochemistry of the atmosphere of Titan: comparison between model and observations. Astrophys.J.Suppl.Ser. 55, 465-506.

Zajfman, D., Rudich, Y., et al., 2003. High resolution mass spectrometry using a linear electrostatic ion beam trap. Int.J.Mass.Spectrom. 229, 55-60.

Zajfman, D., Strasser, D., et al., 2004. Dynamics of stored ions in an electrostatic ion beam trap. Nucl. Instrum.Methods. in Physics Research. A.532, 196-202. 


\section{Tables and Schemes}

Table 1: Composition of the carbocations (up to C8) in Titan's upper atmosphere observed by lon Neutral Mass Spectrometer (INMS) instrument. They are grouped in terms of number of carbon atoms. (See Ali et al., Planet. Space Sci. 2013, and references therein.)

Table 2: Composition of the carbocations observed in INMS measurements extended on the basis of the mechanistic interpretation of the combined INMS and CAPS-IBS observations (See section 3.0). The $\mathrm{CH}_{2}{ }^{+}$ substituted derivatives of bi- and tri- and tetra-cyclic benzenoid conjugated polycyclic aromatic hydrocarbons and the closed-shell gaseous aromatic hydrocarbon cations are also included.

Table 3: The Cassini INMS observed composition of an $\mathrm{N}$-bearing carbocations in Titan's upper atmosphere. Protonated hydrogen cyanide, alkylnitriles, alkenenitriles, alkynenitriles and charged molecules of $\mathrm{N}$-heterocycles (e.g. pyrrole, pyridine) and aniline are also included. See the text for the structure-reactivity analysis.

Table 4: Composition of the nitrogen-substituted complex cabocations in CAPS-IBS measurements. The list also includes the protonated nitriles, the closed-shell charged $\mathrm{N}$-heterocycles and their $\mathrm{CH}_{2}{ }^{+}$ substituted various derivatives. See section 3.0 for the mechanistic interpretation of the chemical composition and molecular structure.

Scheme 1.0: Composition and molecular structure of the carbocations identified in Titan's upper atmosphere. The ortho-bridged and the ortho- and peri- bridged polycyclic hydrocarbons are shown. The systems include the benzyl cation $\left(\mathrm{C}_{7} \mathrm{H}_{7}{ }^{+}\right), \mathrm{CH}_{2}{ }^{+}$substituent derivatives of naphthalene $\left(\mathrm{C}_{11} \mathrm{H}_{9}{ }^{+}\right)$, phenanthrene $\left(\mathrm{C}_{15} \mathrm{H}_{11}{ }^{+}\right)$, pyrene $\left(\mathrm{C}_{17} \mathrm{H}_{11}{ }^{+}\right)$, and chrysene $\left(\mathrm{C}_{19} \mathrm{H}_{13}{ }^{+}\right)$rings, and the perinaphthenyl cation $\left(\mathrm{C}_{13} \mathrm{H}_{9}^{+}\right)$and the $\mathrm{C}_{17} \mathrm{H}_{11}^{+}$ion.

Scheme 2.0. Composition of the organic molecules in Titan's atmosphere at high altitudes observed by the Ion Neutral Mass Spectrometer (INMS) onboard the Cassini spacecraft. The more stable structure among isomeric structures of carbocation is displayed for illustrative purpose only (see also Ali et al. 2013).

Scheme 3.0. Shown are $\mathrm{N}$-heterocycles, aniline and benzonitrile: Composition of the protonated compounds of pyrrole $\left(\mathrm{C}_{4} \mathrm{H}_{5} \mathrm{NH}^{+}\right)$, pyridine $\left(\mathrm{C}_{5} \mathrm{H}_{5} \mathrm{NH}^{+}\right)$, and aniline $\left(\mathrm{C}_{6} \mathrm{H}_{7} \mathrm{NH}^{+}\right)$and also the composition of their corresponding closed shell cations $\mathrm{C}_{4} \mathrm{H}_{4} \mathrm{~N}^{+}, \mathrm{C}_{5} \mathrm{H}_{4} \mathrm{~N}^{+}$and $\mathrm{C}_{6} \mathrm{H}_{5} \mathrm{NH}^{+}$detected in Titan's atmosphere at high altitudes in INMS measurements. The $\mathrm{CH}_{2}{ }^{+}$substituent derivatives of quinoline $\left(\mathrm{C}_{10} \mathrm{H}_{8} \mathrm{~N}^{+}\right)$, nitrogen containing phenanthrene $\left(\mathrm{C}_{14} \mathrm{H}_{10} \mathrm{~N}^{+}\right)$, and the perinaphthenyl cation with a $\mathrm{CH}$ group replaced by a $\mathrm{N}$ atom $\mathrm{C}_{12} \mathrm{H}_{8} \mathrm{~N}^{+}$identified in Titan's ionosphere in the molecular growth process are also shown (see text for a discussion).

Scheme 4.0. The scheme displays the multiple addition of ethylene to the benzyl cation $\mathrm{C}_{7} \mathrm{H}_{7}^{+}$. The chain reaction illustrates the formation of the methylene $\mathrm{CH}_{2}^{+}$substituted derivatives of naphthalene $\mathrm{C}_{11} \mathrm{H}_{9}{ }^{+}$ 
and the perinaphthenyl cation $\mathrm{C}_{13} \mathrm{H}_{9}{ }^{+}$including the formation of a five membered ring fused with a benzene ring, $\mathrm{C}_{9} \mathrm{H}_{7}^{+}$. The scheme is based on the carbon-carbon bond formation dynamics on the potential energy surfaces of elementary reactions of closed-shell ions with polar and nonpolar molecules (see the reference of Ali et al. 2013).

Scheme 5.0. The ortho-fused bi-cyclic and ortho- and peri-fused tri-cyclic systems containing methyl substitution and a single triple bond between ortho carbons are displayed. Some of the corresponding $\mathrm{N}$-heterocycles are also shown.

Scheme 6.0. The scheme displays the reaction pathways of the progression of chain reactions of $\mathrm{C}_{2} \mathrm{H}_{4}$ with $\mathrm{C}_{6} \mathrm{H}_{5} \mathrm{NH}^{+}$to elucidate the formation mechanism of $\mathrm{N}$-heterocycles such as the $\mathrm{CH}_{2}{ }^{+}$monosubstituted derivative of quinoline $\mathrm{C}_{10} \mathrm{H}_{8} \mathrm{~N}^{+}$and the phenalene cation where a $\mathrm{CH}$ group is replaced by an $\mathrm{N}$ atom $\mathrm{C}_{12} \mathrm{H}_{8} \mathrm{~N}^{+}$.

Fig.1. Schematic diagram of the CAPS sensor optics (See Young et al. 2004, Space Sci. Reviews. 114, 1112). 
Table 1.

\begin{tabular}{clll}
\hline C Group & \multicolumn{4}{c}{ Hydrocarbon Composition } \\
\hline $\mathrm{C} 1$ & $\mathrm{CH}_{4}^{+}$ & $\mathrm{CH}_{5}^{+}$ & \\
$\mathrm{C} 2$ & $\mathrm{C}_{2} \mathrm{H}_{3}^{+}$ & $\mathrm{C}_{2} \mathrm{H}_{5}^{+}$ & $\mathrm{C}_{2} \mathrm{H}_{7}^{+}$ \\
$\mathrm{C} 3$ & $\mathrm{C}_{3} \mathrm{H}_{3}^{+}$ & $\mathrm{C}_{3} \mathrm{H}_{5}^{+}$ & $\mathrm{C}_{3} \mathrm{H}_{7}^{+}$ \\
$\mathrm{C} 4$ & $\mathrm{C}_{4} \mathrm{H}_{3}^{+}$ & $\mathrm{C}_{4} \mathrm{H}_{5}^{+}$ & $\mathrm{C}_{4} \mathrm{H}_{7}^{+}$ \\
$\mathrm{C} 5$ & $\mathrm{C}_{5} \mathrm{H}_{5}^{+}$ & $\mathrm{C}_{5} \mathrm{H}_{7}^{+}$ & $\mathrm{C}_{5} \mathrm{H}_{9}^{+}$ \\
$\mathrm{C} 6$ & $\mathrm{C}_{6} \mathrm{H}_{3}^{+}$ & $\mathrm{C}_{6} \mathrm{H}_{5}^{+}$ & $\mathrm{C}_{6} \mathrm{H}_{7}^{+}$ \\
$\mathrm{C} 7$ & $\mathrm{C}_{7} \mathrm{H}_{5}^{+}$ & $\mathrm{C}_{7} \mathrm{H}_{7}^{+}$ & $\mathrm{C}_{7} \mathrm{H}_{9}^{+}$ \\
$\mathrm{C} 8$ & $\mathrm{C}_{8} \mathrm{H}_{3}^{+}$ & & \\
\hline
\end{tabular}

Table 2.

\begin{tabular}{clll}
\hline C Group & \multicolumn{4}{c}{ Composition: Hydrocarbon } \\
\hline $\mathrm{C} 9$ & $\mathrm{C}_{9} \mathrm{H}_{7}^{+}$ & $\mathrm{C}_{9} \mathrm{H}_{9}^{+}$ & \\
$\mathrm{C} 10$ & $\mathrm{C}_{10} \mathrm{H}_{3}^{+}$ & $\mathrm{C}_{10} \mathrm{H}_{9}^{+}$ & $\mathrm{C}_{10} \mathrm{H}_{11}{ }^{+}$ \\
$\mathrm{C} 11$ & $\mathrm{C}_{11} \mathrm{H}_{7}^{+}$ & $\mathrm{C}_{11} \mathrm{H}_{9}^{+}$ & $\mathrm{C}_{11} \mathrm{H}_{11}{ }^{+}$ \\
$\mathrm{C} 12$ & $\mathrm{C}_{12} \mathrm{H}_{9}^{+}$ & $\mathrm{C}_{12} \mathrm{H}_{11}^{+}$ & $\mathrm{C}_{12} \mathrm{H}_{13}{ }^{+}$ \\
$\mathrm{C} 13$ & $\mathrm{C}_{13} \mathrm{H}_{7}^{+}$ & $\mathrm{C}_{13} \mathrm{H}_{9}^{+}$ & $\mathrm{C}_{13} \mathrm{H}_{11}{ }^{+}$ \\
$\mathrm{C} 14$ & $\mathrm{C}_{14} \mathrm{H}_{9}^{+}$ & $\mathrm{C}_{14} \mathrm{H}_{11}^{+}$ & $\mathrm{C}_{14} \mathrm{H}_{13}{ }^{+}$ \\
$\mathrm{C} 15$ & $\mathrm{C}_{15} \mathrm{H}_{11}^{+}$ & $\mathrm{C}_{15} \mathrm{H}_{13}^{+}$ & \\
$\mathrm{C} 16$ & $\mathrm{C}_{16} \mathrm{H}_{13}^{+}$ & & \\
$\mathrm{C} 17$ & $\mathrm{C}_{17} \mathrm{H}_{11}{ }^{+}$ & $\mathrm{C}_{17} \mathrm{H}_{13}{ }^{+}$ & \\
\hline
\end{tabular}

Table 3.

\begin{tabular}{cccl}
\hline C Group & \multicolumn{4}{c}{$\mathbf{N}$-bearing Hydrocarbons } \\
\hline $\mathrm{C} 1$ & $\mathrm{NH}_{4}^{+}$ & & \\
$\mathrm{C} 2$ & $\mathrm{HCNH}^{+}$ & $\mathrm{CH}_{2} \mathrm{NH}_{2}^{+}$ & \\
$\mathrm{C} 3$ & $\mathrm{CH}_{3} \mathrm{CNH}^{+}$ & & \\
$\mathrm{C} 4$ & $\mathrm{HC}_{3} \mathrm{NH}^{+}$ & $\mathrm{C}_{2} \mathrm{H}_{3} \mathrm{CNH}^{+}$ & $\mathrm{C}_{2} \mathrm{H}_{5} \mathrm{CNH}^{+}$ \\
$\mathrm{C} 5$ & $\mathrm{C}_{4} \mathrm{H}_{4} \mathrm{~N}^{+}$ & $\mathrm{C}_{4} \mathrm{H}_{5} \mathrm{NH}^{+}$ & \\
$\mathrm{C} 6$ & $\mathrm{HC}_{5} \mathrm{NH}^{+}$ & $\mathrm{C}_{5} \mathrm{H}_{4} \mathrm{~N}^{+}$ & $\mathrm{C}_{5} \mathrm{H}_{5} \mathrm{NH}^{+}$ \\
$\mathrm{C} 7$ & $\mathrm{C}_{6} \mathrm{H}_{5} \mathrm{NH}^{+}$ & $\mathrm{C}_{6} \mathrm{H}_{7} \mathrm{NH}^{+}$ & \\
\hline
\end{tabular}


Table 4.

\begin{tabular}{ccc}
\hline C Group & \multicolumn{2}{c}{$\mathrm{N}$-bearing Hydrocarbons } \\
\hline $\mathrm{C} 8$ & $\mathrm{HC}_{7} \mathrm{NH}^{+}$ & \\
$\mathrm{C} 9$ & $\mathrm{C}_{8} \mathrm{H}_{6} \mathrm{~N}^{+}$ & $\mathrm{C}_{8} \mathrm{H}_{8} \mathrm{~N}^{+}$ \\
$\mathrm{C} 10$ & $\mathrm{HC}_{9} \mathrm{NH}^{+}$ & $\mathrm{C}_{9} \mathrm{H}_{8} \mathrm{~N}^{+}$ \\
$\mathrm{C} 11$ & $\mathrm{C}_{10} \mathrm{H}_{8} \mathrm{~N}^{+}$ & $\mathrm{C}_{10} \mathrm{H}_{10} \mathrm{~N}^{+}$ \\
$\mathrm{C} 12$ & $\mathrm{HC}_{11} \mathrm{NH}^{+}$ & $\mathrm{C}_{11} \mathrm{H}_{10} \mathrm{~N}^{+}$ \\
$\mathrm{C} 13$ & $\mathrm{C}_{12} \mathrm{H}_{8} \mathrm{~N}^{+}$ & $\mathrm{C}_{12} \mathrm{H}_{10} \mathrm{~N}^{+}$ \\
$\mathrm{C} 14$ & $\mathrm{C}_{13} \mathrm{H}_{10} \mathrm{~N}^{+}$ & $\mathrm{C}_{13} \mathrm{H}_{12} \mathrm{~N}^{+}$ \\
$\mathrm{C} 15$ & $\mathrm{C}_{14} \mathrm{H}_{10} \mathrm{~N}^{+}$ & \\
\hline
\end{tabular}

Organic Chemistry in Titan's Upper Atmosphere and its Astrobiological Consequences: I. Views towards Cassini Plasma Spectrometer (CAPS) and Ion Neutral Mass Spectrometer (INMS) Experiments in Space

A.Ali, E.C.Sittler Jr., D.Chornay, B.R.Rowe, C.Puzzarini

\section{RESEARCH HIGHLIGHTS}

- Organic Aromatic lonic Species in Titan's upper atmosphere

- Detection of Carbocations and Carbanions by the Cassini INMS and CAPS instruments

- Organic synthesis: Direct consequence of the chemistry of carbocations

- On the formation mechanisms for carbanions

- Molecular structures corresponding to composition detected

- Prebiotic atmospheric chemistry

- Theoretical and laboratory investigations in future astronomical observations 


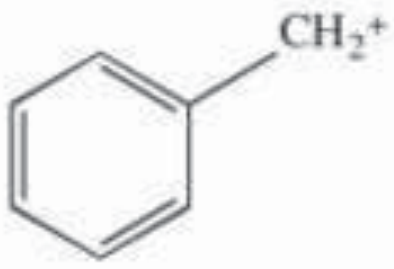

$\mathrm{C}_{7} \mathrm{H}_{7}{ }^{+}$

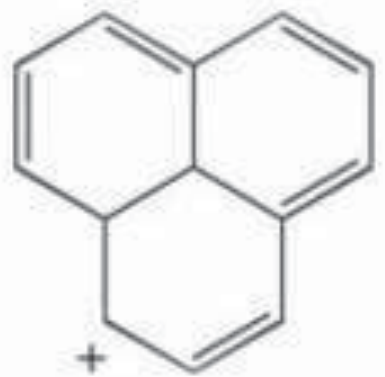

$\mathrm{C}_{13} \mathrm{H}_{9}{ }^{+}$

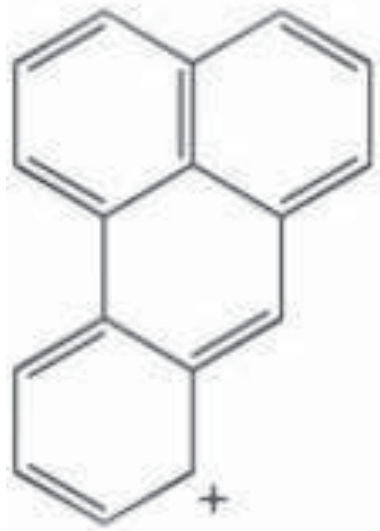

$\mathrm{C}_{17} \mathrm{H}_{11}{ }^{+}$

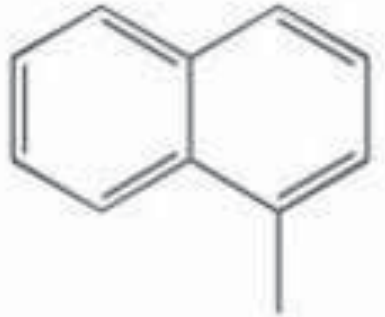

$\mathrm{CH}_{2}{ }^{+}$

$\mathrm{C}_{11} \mathrm{H}_{9}{ }^{+}$

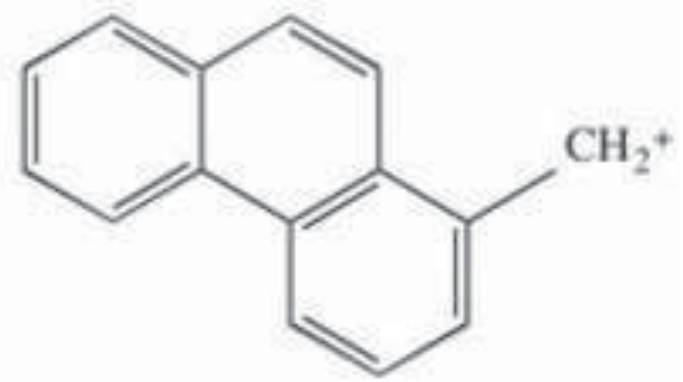

$\mathrm{C}_{15} \mathrm{H}_{11}^{+}$
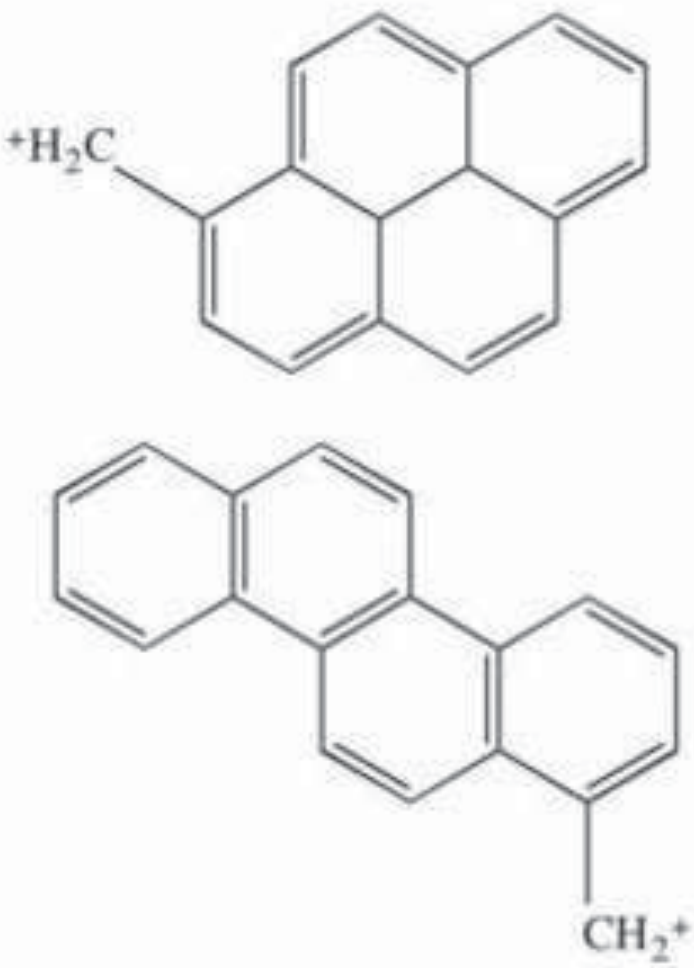

$\mathrm{C}_{19} \mathrm{H}_{13}{ }^{+}$ 
C1

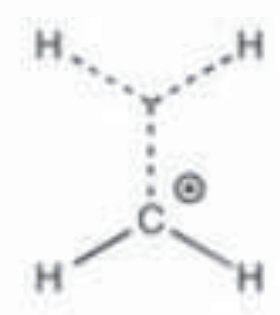

$\mathrm{CH}_{4}{ }^{+}$

C2

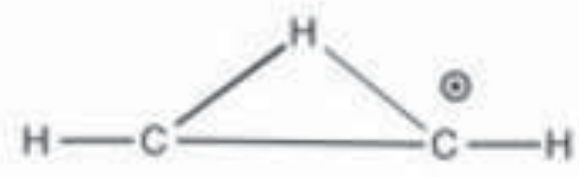

$\mathrm{C}_{2} \mathrm{H}_{3}{ }^{+}$

C3

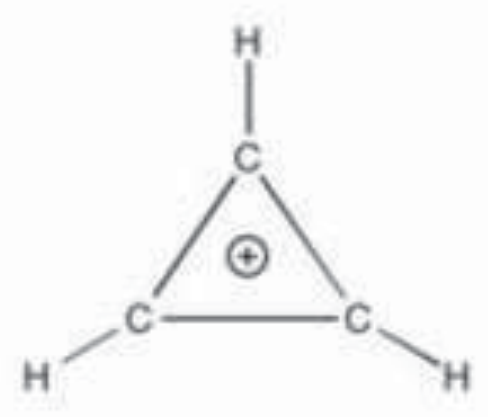

$\mathrm{C}_{3} \mathrm{H}_{3}{ }^{+}$

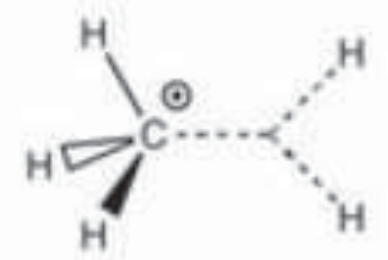

$\mathrm{CH}_{5}{ }^{+}$

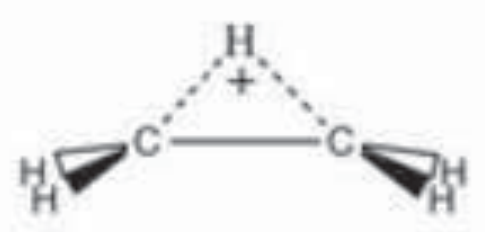

$\mathrm{C}_{2} \mathrm{H}_{5}{ }^{+}$

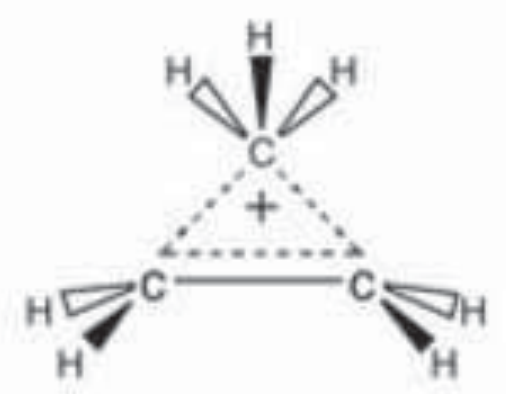

$\mathrm{C}_{3} \mathrm{H}_{7}{ }^{+}$

C4 $\mathrm{cH}=\stackrel{\odot}{=}-\mathrm{c}=\mathrm{CH}_{2}$

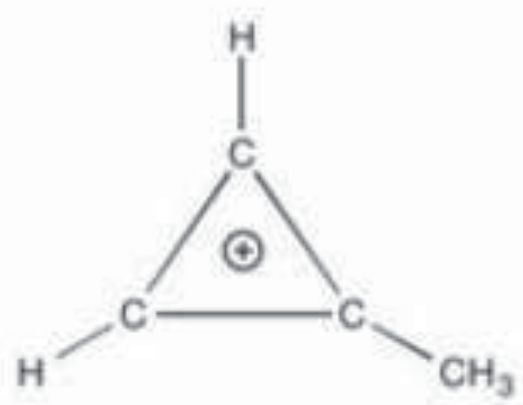

$\mathrm{C}_{4} \mathrm{H}_{3}{ }^{+}$
$\mathrm{C}_{4} \mathrm{H}_{5}{ }^{+}$<smiles>C=CC</smiles>

$\mathrm{C}_{4} \mathrm{H}_{7}+$ 
C5

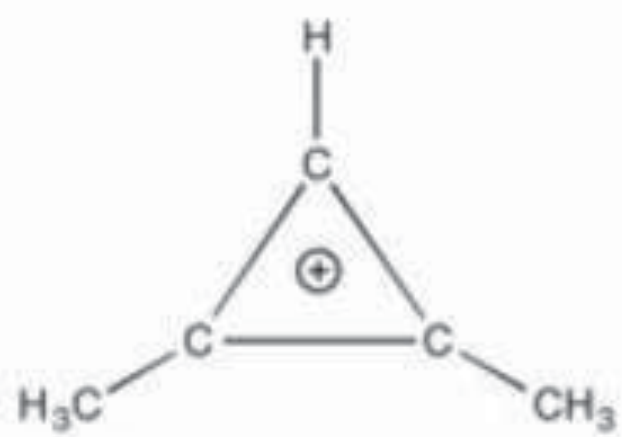

$\mathrm{C}_{5} \mathrm{H}_{7}{ }^{+}$

C6

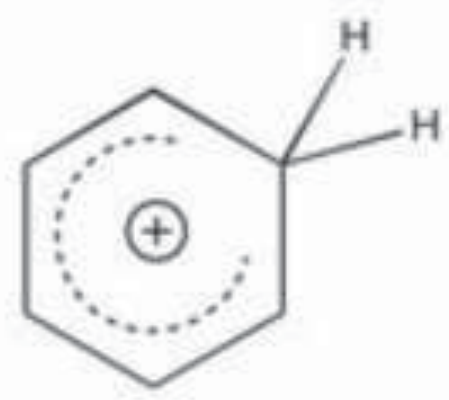

$\mathrm{C}_{6} \mathrm{H}_{7}{ }^{+}$

C7

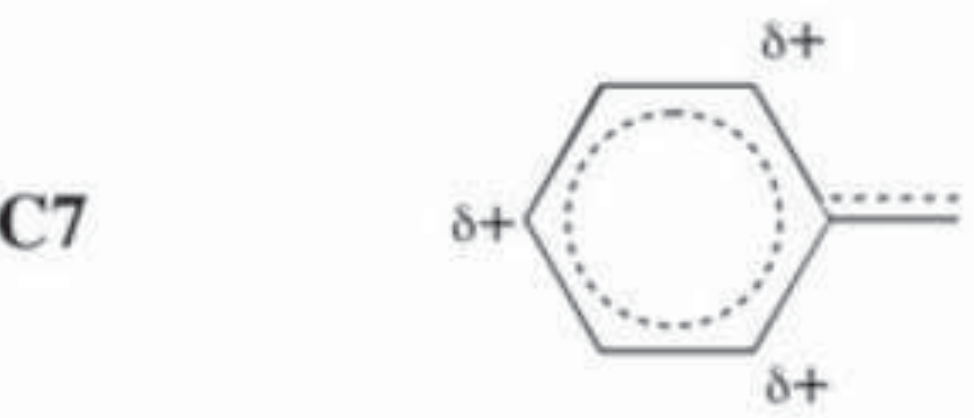

$\mathrm{C}_{7} \mathrm{H}_{7}{ }^{+}$<smiles>CC=CC=CC</smiles>

$\mathrm{C}_{5} \mathrm{H}_{9}{ }^{+}$

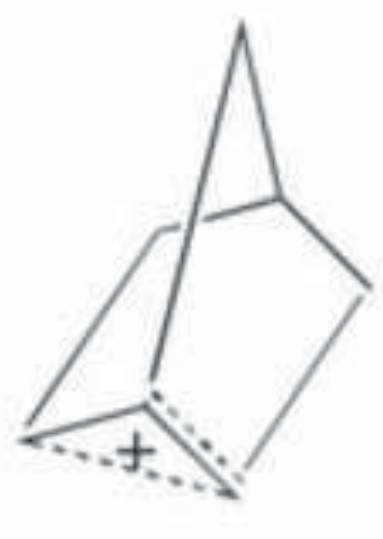

$\mathrm{C}_{7} \mathrm{H}_{11}{ }^{+}$ 


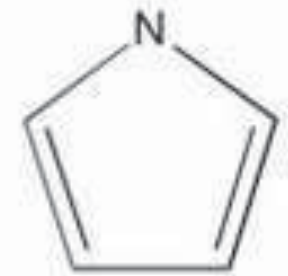

$\mathrm{C}_{4} \mathrm{H}_{5} \mathrm{~N}$

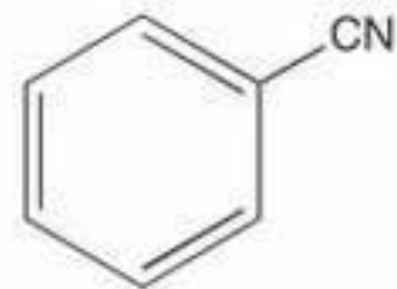

$\mathrm{C}_{7} \mathrm{H}_{5} \mathrm{~N}$

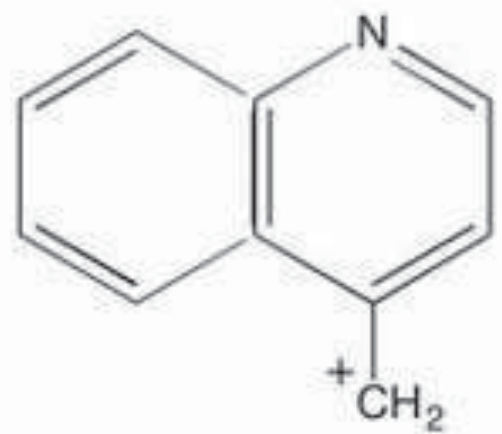

$\mathrm{C}_{10} \mathrm{H}_{8} \mathrm{~N}^{+}$

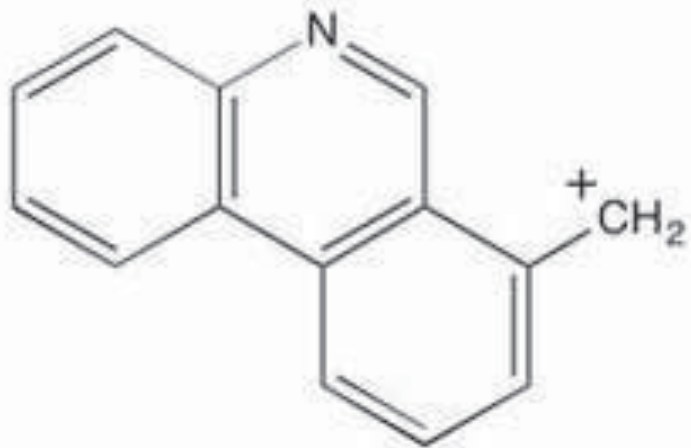

$\mathrm{C}_{14} \mathrm{H}_{10} \mathrm{~N}^{+}$

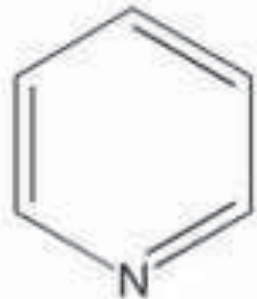

$\mathrm{C}_{5} \mathrm{H}_{5} \mathrm{~N}$

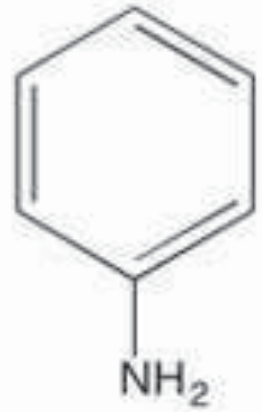

$\mathrm{C}_{6} \mathrm{H}_{7} \mathrm{~N}$

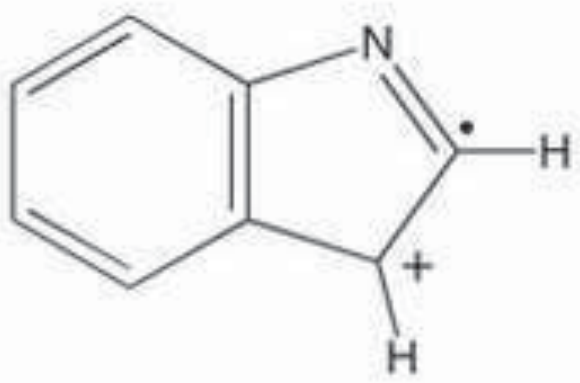

$\mathrm{C}_{8} \mathrm{H}_{6} \mathrm{~N}^{+}$

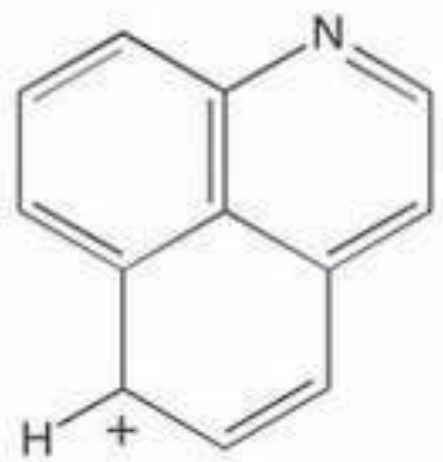

$\mathrm{C}_{12} \mathrm{H}_{8} \mathrm{~N}^{+}$ 

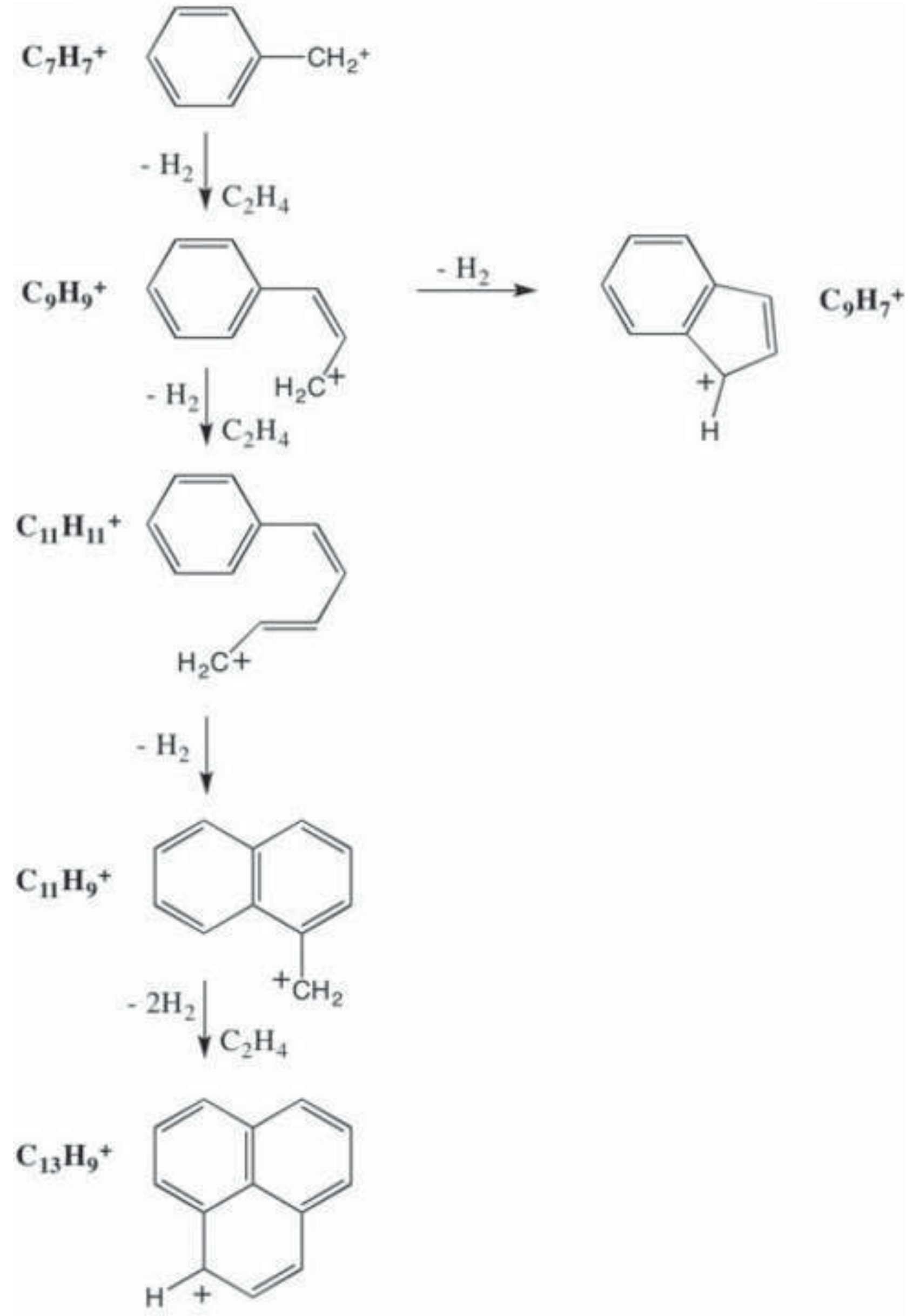

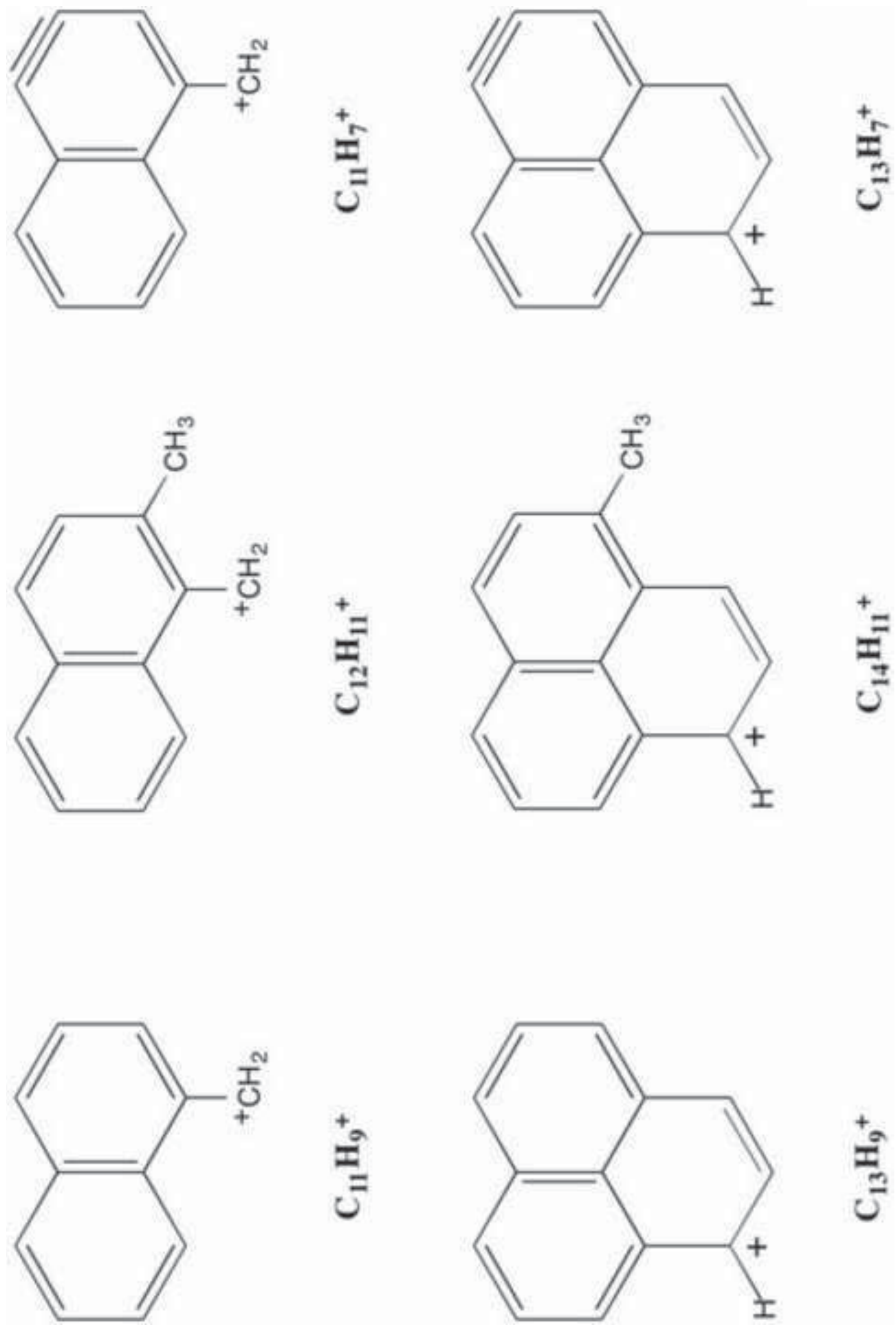

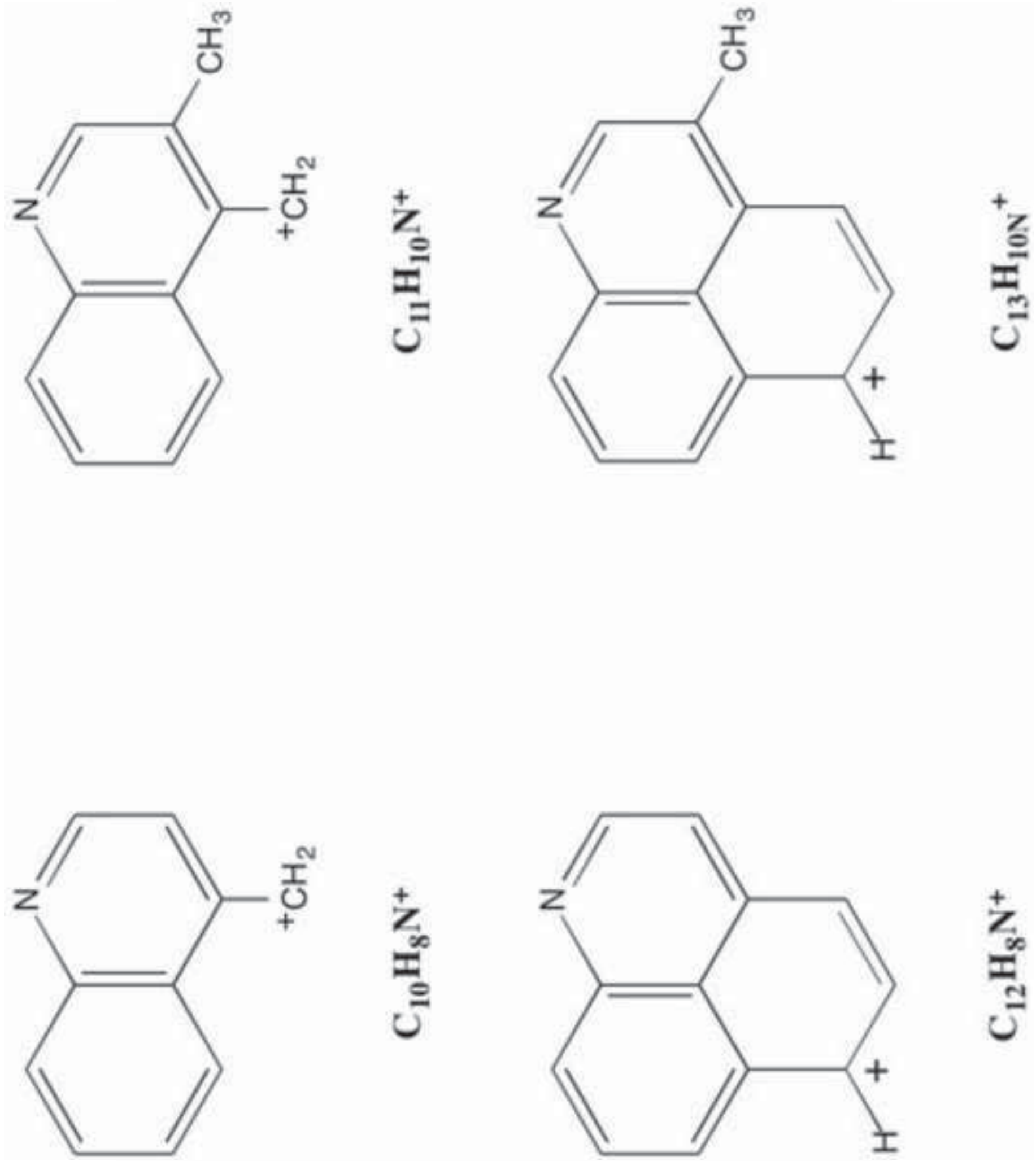
$\mathrm{C}_{6} \mathrm{H}_{6} \mathrm{~N}^{+}$

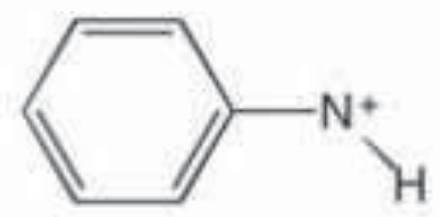

$-\mathrm{H}_{2} \downarrow_{\mathrm{C}_{2} \mathrm{H}_{4}}$

$\mathrm{C}_{8} \mathrm{H}_{8} \mathrm{~N}^{+}$

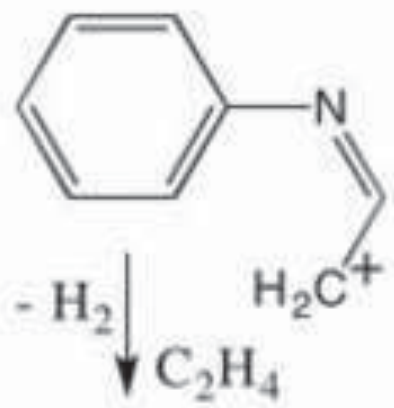

$\stackrel{-\mathrm{H}_{2}}{\longrightarrow}$

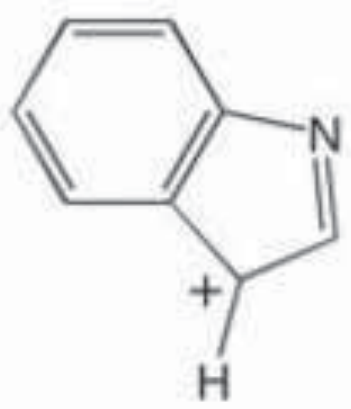

$\mathrm{C}_{8} \mathrm{H}_{6} \mathrm{~N}^{+}$

$\mathrm{C}_{10} \mathrm{H}_{10} \mathrm{~N}^{+}$

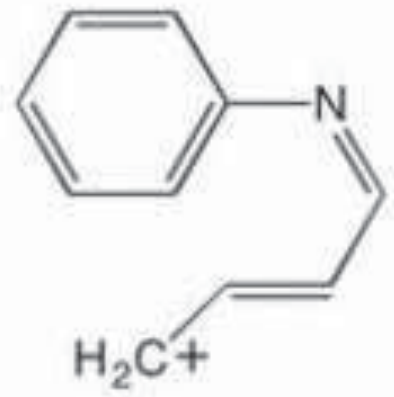

$\mathrm{C}_{10} \mathrm{H}_{8} \mathrm{~N}^{+}$

$-\mathrm{H}_{2}$

$\mathrm{C}_{12} \mathrm{H}_{8} \mathrm{~N}^{+}$<smiles>CCc1ccnc2ccccc12</smiles>

$H^{-}+$<smiles></smiles> 


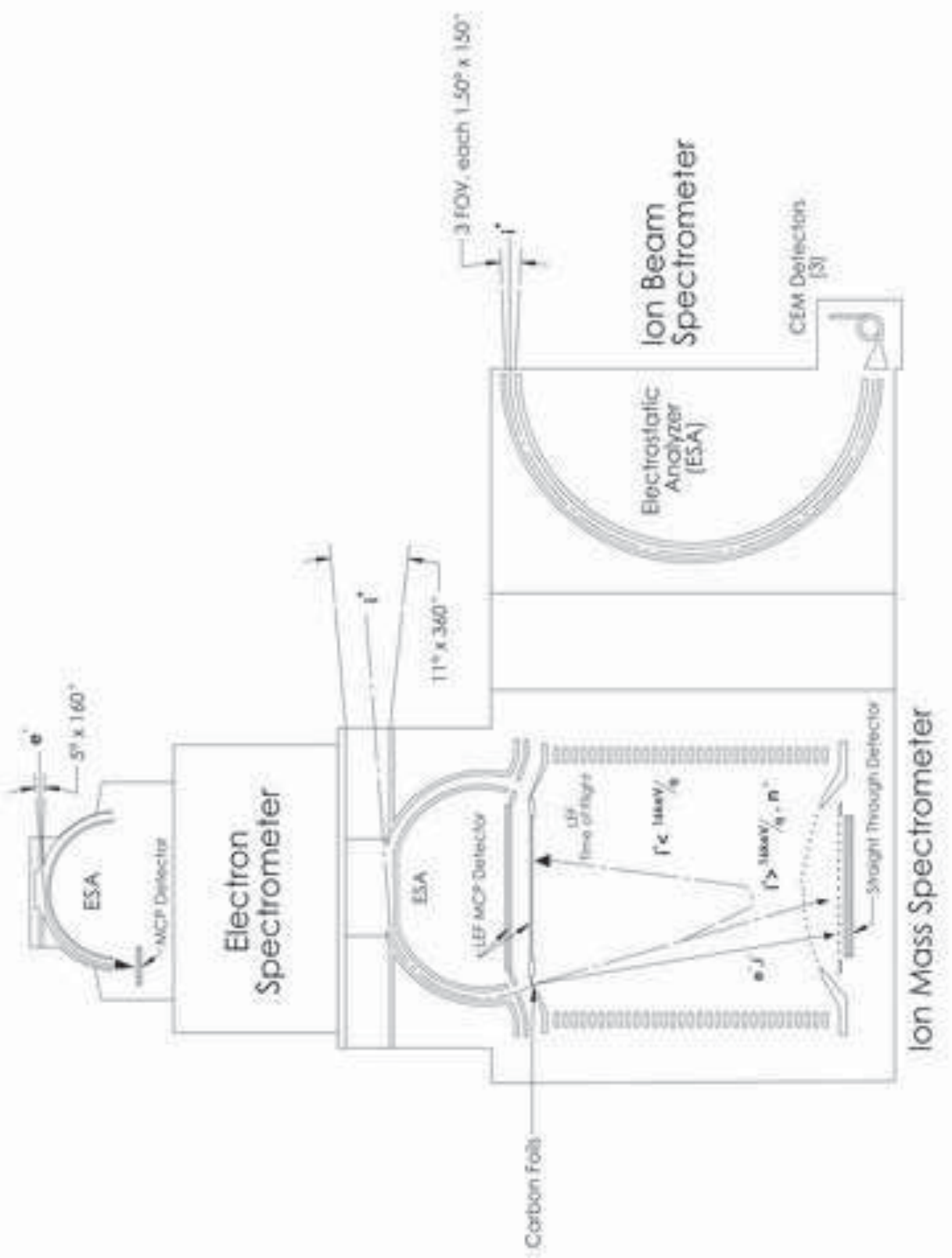

